University of Wollongong

Research Online

Australian Institute for Innovative Materials -

Papers

Australian Institute for Innovative Materials

$1-1-2019$

\title{
A hierarchical porous Fe-N impregnated carbon-graphene hybrid for high- performance oxygen reduction reaction
}

\author{
Sihui Wang \\ University of Wollongong \\ Xiao Yan \\ University of Wollongong, xiaoy@uow.edu.au \\ Kuang-Hsu Wu \\ University of New South Wales \\ Xuemin Chen \\ Hebei University of Science and Technology \\ Jianmin Feng \\ Tianjin Normal University
}

See next page for additional authors

Follow this and additional works at: https://ro.uow.edu.au/aiimpapers

Part of the Engineering Commons, and the Physical Sciences and Mathematics Commons

Research Online is the open access institutional repository for the University of Wollongong. For further information contact the UOW Library: research-pubs@uow.edu.au 


\title{
A hierarchical porous Fe-N impregnated carbon-graphene hybrid for high- performance oxygen reduction reaction
}

\author{
Abstract \\ A Fe-N impregnated carbon in a hybrid with in-situ grown graphene from hierarchical porous carbon has \\ been obtained for high-performance oxygen reduction reaction (ORR) catalysis. This hybrid material \\ combines the desirable characteristics for the ORR, including Fe-N active sites, high surface area, good \\ electron conductivity, and hierarchical channels for mass diffusion. As a result, this catalyst exhibits a \\ very positive reaction onset potential ( $0.05 \mathrm{~V}$ vs. $\mathrm{Ag} / \mathrm{AgCl})$, a high ORR current density, and a complete \\ four-electron ORR pathway, which are even better than a commercial $20 \% \mathrm{Pt} / \mathrm{C}$ catalyst. We further reveal \\ the synergistic ORR enhancement from the controlled Fe-N impregnation in the doped carbon-graphene \\ hybrid

\section{Disciplines} \\ Engineering | Physical Sciences and Mathematics

\section{Publication Details} \\ Wang, S., Yan, X., Wu, K., Chen, X., Feng, J., Lu, P., Feng, H., Cheng, H., Liang, J. \& Dou, S. Xue. (2019). A \\ hierarchical porous Fe-N impregnated carbon-graphene hybrid for high-performance oxygen reduction \\ reaction. Carbon, 144 798-804.

\section{Authors} \\ Sihui Wang, Xiao Yan, Kuang-Hsu Wu, Xuemin Chen, Jianmin Feng, Pengyi Lu, Hou Feng, Hui-Ming Cheng, \\ Ji Liang, and Shi Xue Dou
}




\section{A Hierarchical Porous Fe-N Impregnated Carbon-Graphene Hybrid for}

\section{High-Performance Oxygen Reduction Reaction}

Sihui Wang, ${ }^{[\mathrm{a}, \mathrm{b}] \ddagger}$ Xiao Yan ${ }^{[\mathrm{c}]}{ }^{\ddagger}$ Kuang-Hsu Wu, ${ }^{[\mathrm{d}]} *$ Xuemin Chen, ${ }^{[\mathrm{e}]}$ Hui-Ming Cheng, ${ }^{[\mathrm{f}]}$, Ji Liang, ${ }^{[\mathrm{a}] *}$ and Shi Xue Dou ${ }^{[\mathrm{a}]}$

a Institute for Superconducting \& Electronic Materials, Australian Institute of Innovative Materials, The University of Wollongong, Innovation Campus, North Wollongong, NSW 2500, Australia

${ }^{b}$ School of Aeronautics and Astronautics, Tianjin Sino-German University of Applied Sciences, Tianjin 300350, China

${ }^{c}$ Guangdong Key Laboratory of Membrane Materials and Membrane Separation, Guangzhou Institute of Advanced Technology, Chinese Academy of Sciences, Guangzhou, Guangdong, 511458, China

${ }^{d}$ Particles and Catalysis Research Group, School of Chemical Engineering, The University of New South Wales, Sydney, NSW 2052, Australia

e School of Materials Science and Engineering, Tianjin University, Tianjin, 300072, China

${ }^{f}$ Advanced Carbon Division, Shenyang National Laboratory for Materials Science, Institute of Metal Research, Chinese Academy of Science, Shenyang, 110016, Liaoning, China

Corresponding authors: Dr. Kuang-Hsu Wu (kuang-hsu.wu@unsw.edu.au) and Dr. Ji Liang (liangj@uow.edu.au)

$\$$ These authors contribute equally to this paper. 
Abstract: A Fe-N impregnated carbon in a hybrid with in-situ grown graphene from hierarchical porous carbon has been obtained for high-performance oxygen reduction reaction (ORR) catalysis. This hybrid material combines the desirable characteristics for the ORR, including Fe-N active sites, high surface area, good electron conductivity, and hierarchical channels for mass diffusion. As a result, this catalyst exhibits a very positive reaction onset potential (-0.05 V vs. $\mathrm{Ag} / \mathrm{AgCl})$, a high ORR current density, and a complete four-electron ORR pathway, which are even better than a commercial $20 \% \mathrm{Pt} / \mathrm{C}$ catalyst. We further reveal the synergistic ORR enhancement from the controlled $\mathrm{Fe}-\mathrm{N}$ impregnation in the doped carbon-graphene hybrid.

\section{Introduction}

The oxygen reduction reaction (ORR) is the critical process governing the performance of a series of devices for the conversion and storage of energy, such as low-temperature fuel cells and metal-air batteries. ${ }^{[1,2]}$ Due to the sluggish nature of the ORR at low temperature, catalysts such as Pt-based materials are always required to accelerate the ORR. However, multiple disadvantages, especially their high price and low reserve, have made Pt-based catalysts economically unfavorable for large-scale production, and have thus hindered the commercialization of these devices. ${ }^{[3]}$ To deal with this problem, extensive efforts have been devoted to developing a low-cost but similarly active catalyst, including metal-free ${ }^{[3-8]}$ and non-precious metal catalysts. ${ }^{[9-19]}$ 
Among these materials, iron-nitrogen co-modified carbon $(\mathrm{Fe}-\mathrm{N}-\mathrm{C})$ is particularly interesting because of their high ORR activity. ${ }^{[20,21]}$ This has attracted a strong interest in exploring a variety of $\mathrm{Fe}-\mathrm{N}-\mathrm{C}$ materials with a diverse range of structures like nanotubes, ${ }^{[12]}$ microspheres, ${ }^{[22]}$ tetra-pods, ${ }^{[23]}$ or nanosheets. ${ }^{[10]}$ Despite their excellent activity, the iron species tend to sinter into large particles in these materials, restricting the exposure of the Fe species for proper functioning. These iron oxide/carbide particles are also always wrapped by a graphitic layer, preventing them from contacting the electrolyte and thus lowering the specific catalytic activity of the catalysts as well. Besides, the presence of the iron particles have always made the control over carbon's microstructure very difficult, because these iron-containing particles not only act as the potential active sites for ORR but also promote the deformation of the original carbon frameworks, leading to the uncontrollable formation of graphitic nanostructures, especially at high annealing temperatures during the fabrication. ${ }^{[12,23-25]}$ Based on these considerations, rational microstructural design and controllable fabrication of Fe-N containing carbon-based material for ORR is the bottleneck to enhance their ORR catalytic performances further.

To most efficiently utilize the Fe-N sites in such Fe-N-C materials, it is generally required that the $\mathrm{Fe}$ and $\mathrm{N}$ species should be atomically and uniformly dispersed on carbon matrix and the formation of large iron particles should be avoided. On the other hand, hierarchical channels with macropores and mesopores in carbon matrix are also desirable to facilitate the mass transfer and improve the exposure of the active $\mathrm{Fe}-\mathrm{N}$ sites. Moreover, the catalyst particles should also be interconnected to form a 
conductive network rather than being isolated in order to enhance the electron conductivity for the electrochemical process. ${ }^{[14,15]}$

With the purpose of maximizing the exposure of active Fe-N sites while constructing the optimal hierarchical porous framework, we herein report a hierarchical porous $\mathrm{Fe}-\mathrm{N}$ impregnated carbon-graphene hybrid material. On this material, Fe-N moieties exist on the hierarchical porous carbons that are interlinked via in-situ formed graphene (denoted as Fe-N-G-HPC), which has successfully integrated the merits of both the hierarchical structure and desirable chemical characteristics. Consequently, this material carries an outstanding ORR catalytic capability that is even better than the state-of-the-art $\mathrm{Pt} / \mathrm{C}$ catalyst in an alkaline electrolyte.

\section{Experimental Section}

\subsection{Chemicals}

Melamine (99\%), hydroxide pellets $(\mathrm{NaOH}, 99 \%)$, ethanol (EtOH, absolute), phenol (99\%), formaldehyde solution (37\%), iron(II) chloride tetrahydrate $\left(\mathrm{FeCl}_{2} \cdot 4 \mathrm{H}_{2} \mathrm{O}, 98 \%\right)$, iron(III) chloride hexahydrate $\left(\mathrm{FeCl}_{3} \cdot 6 \mathrm{H}_{2} \mathrm{O}, 97 \%\right)$, cyclohexane $(99.5 \%)$, acetone (> 99\%), acetylacetone (99\%) were purchased from Sigma-Aldrich and directly used without further treatment or purification.

\subsection{Preparation of resol}

Typically, $10 \mathrm{~g}$ of phenol was heated until melt at $42{ }^{\circ} \mathrm{C}$ in a capped bottle. Then $2.1 \mathrm{~g}$ of 20 wt. $\% \mathrm{NaOH}$ aqueous solution was added by drop with continuous stirring at $100 \mathrm{rpm}$. Afterward, $17.7 \mathrm{~g}$ of $37 \mathrm{wt} . \%$ formaldehyde solution was added by drop, 
and the heating temperature was raised to $70{ }^{\circ} \mathrm{C}$. The solution was heated and stirred for another $1 \mathrm{~h}$, and then cooled to room temperature. After that, the $\mathrm{pH}$ of the solution was adjusted with $2 \mathrm{M} \mathrm{HCl}$ aqueous solution until 7. Then, water was removed by rotary evaporation at $45{ }^{\circ} \mathrm{C}$, and the product was diluted into a $20 \mathrm{wt} . \%$ EtOH solution. During the dilution, the separated $\mathrm{NaCl}$ was filtered, resulting in a pale yellow solution.

\subsection{Preparation of Fe-contained porous resin (Fe-OPR)}

Fe-OPR was prepared using F127 and polystyrene (PS) spheres as the sacrificial pore-directing agents. $1.7 \mathrm{~g} \mathrm{~F} 127$ and $17 \mathrm{ml} \mathrm{EtOH}$ were mixed at $50{ }^{\circ} \mathrm{C}$ with continuous stir for $30 \mathrm{~min}$. Then $8.5 \mathrm{~g}$ resol solution was added and kept stirred for another 20 min. $0.12 \mathrm{~g} \mathrm{FeCl}_{3} \cdot 6 \mathrm{H}_{2} \mathrm{O}$ and $0.09 \mathrm{~g} \mathrm{FeCl}_{2} \cdot 4 \mathrm{H}_{2} \mathrm{O}$ were dissolved in $16 \mathrm{ml}$ EtOH and added into the above solution. Then $352 \mu$ acac was added into the solution with stir. The above solution was added by drop into the evaporation dish with $10 \mathrm{~g}$ of dry PS template. After that, the dish was kept under vacuum for $10 \mathrm{~min}$. Then, the mixture was dried in air at room temperature. After that, the material was heated at $100{ }^{\circ} \mathrm{C}$ for $24 \mathrm{~h}$ in air and then at $350{ }^{\circ} \mathrm{C}$ in $\mathrm{N}_{2}$ for $3.5 \mathrm{~h}$. The obtained solid was slightly crushed and washed in an excessive amount of acetone and cyclohexane mixture at $60{ }^{\circ} \mathrm{C}(1: 1$ in volume $)$ twice to remove the residual template. The powder was filtered and dried at $100{ }^{\circ} \mathrm{C}$ overnight, resulting in a Fe-contained ordered porous resin (denoted as Fe-OPR). For comparison, Fe-free OPR was prepared following the same procedure except for without the addition of Fe salts.

2.4 Preparation of Fe-N-G-HPC and other control samples 
To prepare the Fe-N-G-HPC, the Fe-OPR was finely ground with 5 times weight of melamine and 5 times weight of $\mathrm{g}-\mathrm{C}_{3} \mathrm{~N}_{4}$ and pyrolyzed at $750{ }^{\circ} \mathrm{C}, 900{ }^{\circ} \mathrm{C}, 1050{ }^{\circ} \mathrm{C}$, respectively. The Fe-N-G-HPC-750, Fe-N-G-HPC-900, Fe-N-G-HPC-1050 were obtained.

To prepare Fe-N-HPC without the in-situ formed graphene, the same amount of melamine and $\mathrm{g}-\mathrm{C}_{3} \mathrm{~N}_{4}$ was put in a separate boat with a cover. Then the materials underwent the same heating process as above.

To prepare the Fe-HPC, Fe-OPR was heated without any melamine or $\mathrm{g}-\mathrm{C}_{3} \mathrm{~N}_{4}$ through the heating program as used for the Fe-N-G-HPC.

To prepare N-HPC, Fe-free OPR was put in a boat and then 5 times weight of melamine and 5 times weight of $\mathrm{g}-\mathrm{C}_{3} \mathrm{~N}_{4}$ was put in a separate boat with a cover. Then the materials underwent the same heating process as used for Fe-N-G-HPC.

To prepare HPC, Fe-free OPR was heated without any melamine or $\mathrm{g}-\mathrm{C}_{3} \mathrm{~N}_{4}$ through the heating program as used for the Fe-N-G-HPC.

\subsection{Characterizations}

Nitrogen adsorption-desorption isotherm was recorded on Tristar II (Micrometrics) at $-196{ }^{\circ} \mathrm{C}$. The pore size distribution was calculated by Barrett-Joyner-Halenda (BJH) model using adsorption branch data of the nitrogen isotherms. The specific surface area was calculated using adsorption data at the relative pressure range of $\mathrm{P} / \mathrm{P}_{0}=0.05-0.3$ by Brunauer-Emmett-Teller (BET) model.

Microstructures of the samples were observed on TEM (Tecnai G2 Spirit TEM) and SEM (Quanta FEG 450, FEI). High-resolution TEM images were obtained on 
JEM-2100 microscopy. Elemental mapping was conducted using EDAX detector attached on JEM-2100. X-ray photoelectron spectroscopy (XPS) analysis was carried out on AXIS Ultra spectrometer (Kratos Analytical Ltd.) with monochromated Al K $\alpha$ radiation at a pressure of $c a .5 \times 10^{-9} \mathrm{~Pa}$. Binding energies were calibrated using the adventitious carbon $(\mathrm{C} 1 \mathrm{~s})=284.6 \mathrm{eV}$. X-Ray diffraction $(\mathrm{XRD})$ was performed on Miniflx-600 (Rigaku Ltd.) at ambient conditions using a $\mathrm{Cu} \mathrm{K} \alpha \mathrm{X}$-ray.

\subsection{Electrochemical test}

Electrochemical tests were carried out using an analysis station $(\mathrm{CHI} 760 \mathrm{C}, \mathrm{CH}$ Instruments, USA) and a common three-electrode electrochemical cell containing a Pt wire and an $\mathrm{Ag} / \mathrm{AgCl} / \mathrm{KCl}(3 \mathrm{M})$ reference electrode as the counter and reference electrode respectively and $100 \mathrm{ml}$ of $0.1 \mathrm{M} \mathrm{KOH}$ aqueous electrolyte. To prepare the working electrode, a homogeneous catalyst ink was firstly prepared by homogeneously dispersing $2 \mathrm{mg}$ of the catalyst in $1 \mathrm{ml}$ of DI water with slight ultrasonication. $40 \mu \mathrm{l}$ of the ink was dripped onto the respective electrodes, i.e., a glassy carbon electrode for cyclic voltammetry (CV) test, a rotating disk electrode (RDE) for RDE test, a rotating ring-disc electrode (RRDE) for the RRDE test, respectively. Then, $10 \mu \mathrm{l}$ of $0.5 \mathrm{wt} \%$ Nafion aqueous solution was dripped on the electrode and dried at room temperature as the binder. The CV test was performed in $\mathrm{O}_{2} / \mathrm{N}_{2}$ saturated electrolyte at $100 \mathrm{mV} \mathrm{s}^{-1}$. The linear sweep voltammograms (LSVs) of RDE were recorded in $\mathrm{O}_{2}$ saturated $0.1 \mathrm{M} \mathrm{KOH}$ with a scan rate of $5 \mathrm{mV} \mathrm{s}^{-1}$ at various rotating speeds from 0 to $2000 \mathrm{rpm}$ for ORR. After each scan, the electrolyte was saturated with $\mathrm{O}_{2}$ again for 5 minutes. The sample was tested 3 times to avoid 
any incidental error. The LSVs of RRDE were recorded in $\mathrm{O}_{2}$ saturated $0.1 \mathrm{M} \mathrm{KOH}$ at $1600 \mathrm{rpm}$. The disc was set to scan at $5 \mathrm{mV} \mathrm{s}^{-1}$ on the disc electrode from $0.2 \mathrm{~V}$ to $-0.8 \mathrm{~V}$ vs. $\mathrm{Ag} / \mathrm{AgCl}$ and the ring was set at $0.5 \mathrm{~V}$ vs. $\mathrm{Ag} / \mathrm{AgCl}$. The collecting efficiency of the RRDE (N) was 0.37 . The peroxide yield $\left(\mathrm{HO}_{2}{ }^{-} \%\right)$ and the electron transfer number (n) was calculated as follows:

$$
\begin{aligned}
& \mathrm{HO}_{2}{ }^{-} \%=200 \times \mathrm{I}_{\mathrm{r}} / \mathrm{N} /\left(\mathrm{I}_{\mathrm{d}}+\mathrm{I}_{\mathrm{r}} / \mathrm{N}\right) \\
& \mathrm{n}=4 \times \mathrm{I}_{\mathrm{d}} /\left(\mathrm{I}_{\mathrm{d}}+\mathrm{I}_{\mathrm{r}} / \mathrm{N}\right)
\end{aligned}
$$

Where $I_{d}$ is the disc current and $I_{r}$ is the ring current.

\section{Results and Discussion}

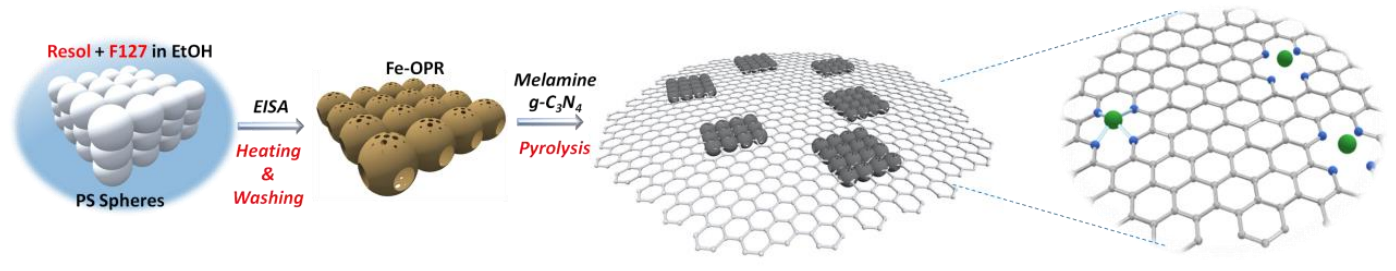

Figure 1. The preparation of Fe-N-G-HPC material.

To prepare the Fe-N-G-HPC material, a dual-template method was adopted by using polystyrene (PS) sphere and tri-block copolymer (Pluronic F127) as the templates for ordered macropores and mesopores, respectively (Figure 1). An aqueous suspension containing PS sphere $\left(0.1 \mathrm{~g} \mathrm{ml}^{-1}\right)$ was evaporated under the ambient condition to allow the PS spheres packing into an ordered monolith. The PS monolith was immersed into an ethanol solution containing low-molecular resol (the carbon precursor), $\mathrm{Fe}^{2} \beta^{3+}$ chloride, and F127. Acetylacetone was also employed into the system for better dispersion of the Fe species in the material. Then the mixture was dried at room temperature to allow the evaporation-induced self-assembly (EISA) of 
F127 and resol to form the mesostructures in the voids between the packed PS spheres. Then the obtained material was heated at $100{ }^{\circ} \mathrm{C}$ and $350{ }^{\circ} \mathrm{C}$ to polymerize the resol into a rigid resin. The residual templates were removed by washing in a blend of cyclohexane and acetone, leaving a hierarchical porous resin containing Fe species. The resin was finely mixed with melamine and graphitic carbon nitride $\left(\mathrm{g}-\mathrm{C}_{3} \mathrm{~N}_{4}\right)$, and heated in $\mathrm{N}_{2}$ at $900{ }^{\circ} \mathrm{C}$ to form Fe-N-G-HPC. The hybrid was also synthesized at 750 ${ }^{\circ} \mathrm{C}$ and $1050{ }^{\circ} \mathrm{C}$ (denoted as Fe-N-G-HPC-750 or -1050 , respectively) to study the influence of annealing temperatures on the catalytic ORR activity. An analog of HPC (without $\mathrm{Fe}$ and $\mathrm{N}$ dopants), Fe-HPC (without $\mathrm{N}$ dopants), N-HPC (without Fe dopants), and Fe-N-HPC (without the in-situ formed graphene) was also prepared in a similar way to further study the roles of the individual species in the material and to confirm the synergistic effect of the Fe-N moieties for ORR.

Typically, the as-prepared Fe-N-G-HPC hybrid shows a monolithic appearance after the thermal treatment (Figure 2a), which is distinctly different from the loose powder form of Fe-N-HPC material (without the in-situ formed graphene). This indicates that a three-dimensional and inter-connecting matrix was established among the HPC microblocks in the Fe-N-G-HPC composite. Such an interlinked 3D structure was further characterized by SEM and TEM (Figure 2b, c and S1-3), showing that the carbon microblocks ( $c a$. a few micrometers in size) with the honeycomb-structured and ordered macropores are connected by a large number of wrinkled graphene sheets. The high-resolution (HR) TEM images in Figure $2 \mathrm{~d}$ confirms the existence of tubular mesopores on the walls of the macropores, which is typical of those pore structures 
derived from F127 soft templates and act as the main contributor to the large specific area of the material.
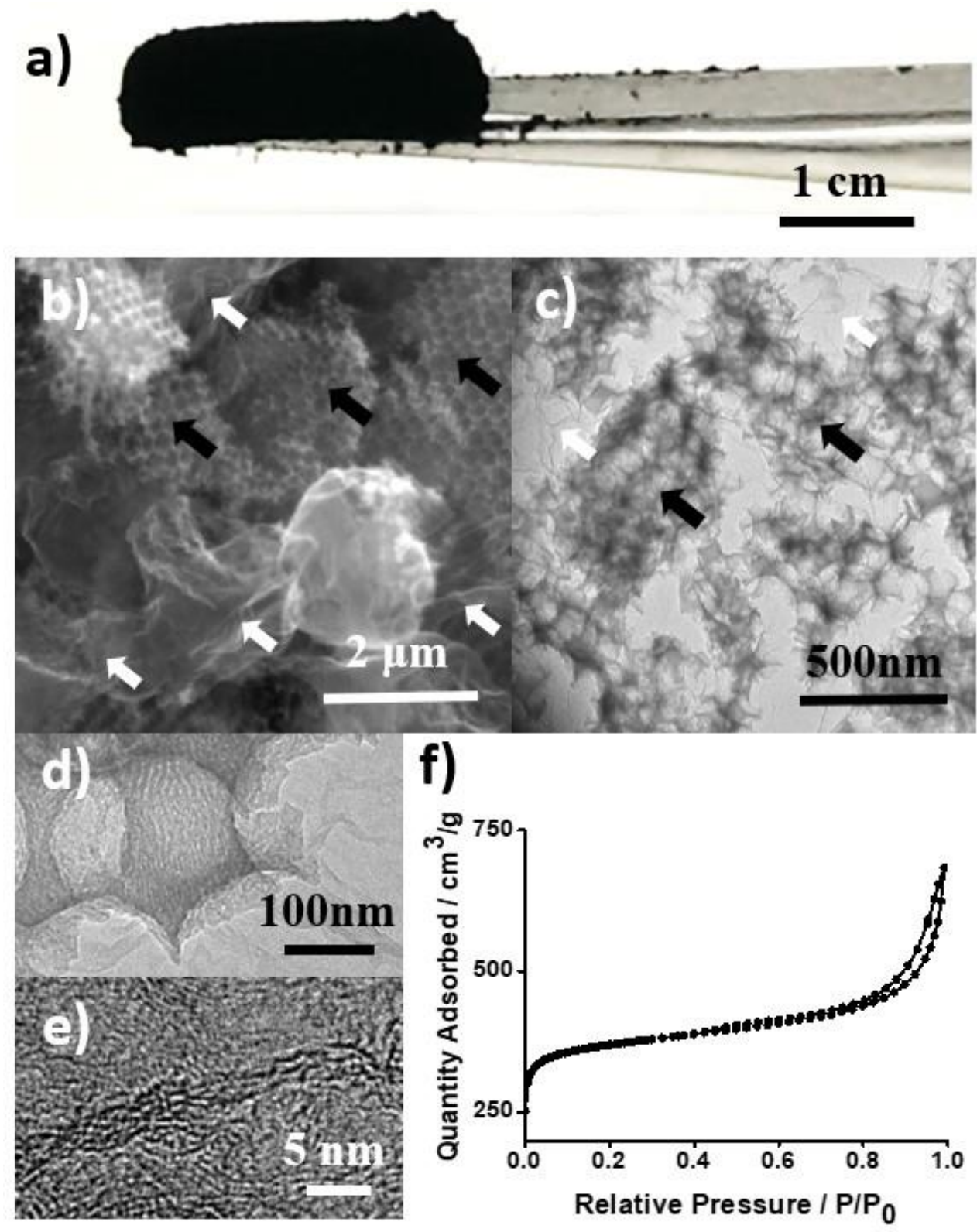

Figure 2. Characterizations of Fe-N-G-HPC material. (a) The optical image of the sample after the pyrolysis held on a tweezer, (b) SEM and (c-e) TEM images of different sections of the sample (white arrow: in-situ formed graphene, black arrow: hierarchical porous carbon, (f) Nitrogen adsorption and desorption isotherms. 
Nitrogen adsorption-desorption isotherms of the samples were collected to study the porosity of the materials (Figure $2 \mathrm{f}$ and S4). Both Fe-N-G-HPC and Fe-N-HPC exhibited a similarly high surface area (1144 and $1132 \mathrm{~m}^{2} \mathrm{~g}^{-1}$, respectively) and identical isotherms with a hysteresis loop extending from medium to high pressure regions. The hysteresis feature is typical of hierarchical porous carbon, which is due to the capillary condensation in tubular mesopores and the neck part of cage-like macropores. The increase in the low pressure region further suggests the abundance of micropores. This result indicates that the in-situ formed graphene does not compromise the excellent hierarchical structures on this material. The in-situ grown graphene nanosheets were also observed by HRTEM, as shown in Figure 2e and S2. The images show that the graphene sheets consist of small-sized and patch-like graphitic domains and pores. The wrinkled domain on the graphene sheet has a thickness of $c a .1 .5 \mathrm{~nm}$, corresponding to 3-5 single graphene layers.

The chemistry of the composites was analyzed by XPS. Figure 3a, S5, and S6 show the presence of $\mathrm{N}$ and $\mathrm{Fe}$ species at a similar amount in the carbon matrix of Fe-N-G-HPC and Fe-N-HPC materials. The detailed chemistry status of these elements is further studied by high-resolution XPS scan. Specifically, the N1s spectrum can be deconvoluted into three major $\mathrm{N}$ species centered at ca. $401.2 \mathrm{eV}$, $399.5 \mathrm{eV}$ and $398.2 \mathrm{eV}$, corresponding to graphitic $\mathrm{N}$, pyrrolic $\mathrm{N}$ and pyridinic $\mathrm{N}$, respectively. ${ }^{[14]}$ It is hard to find the corresponding N-Fe species in the N1s spectrum, which might be caused by the low content of Fe species in the material and has been reported in other studies. ${ }^{[12,15]}$ Besides, from the high-resolution C1s spectrum, 
typical carbon species, including $-\mathrm{C}=\mathrm{C}-,-\mathrm{C}-\mathrm{OH},-\mathrm{C}-\mathrm{N}$ species, can be identified. ${ }^{[6]}$ In the high-resolution Fe XPS spectrum, the peaks at $708 \mathrm{eV}$ and $710 \mathrm{eV}$ can be assigned to $\mathrm{Fe} 2 \mathrm{p}_{3 / 2}$ of $\mathrm{Fe}^{2+}$ and $\mathrm{Fe}^{3+}$, respectively, the peak at $721 \mathrm{eV}$ is attributed to $\mathrm{Fe} 2 \mathrm{p}_{1 / 2}$ of $\mathrm{Fe}^{2+}$ and $\mathrm{Fe}^{3+}$, the peak at $714.3 \mathrm{eV}$ is assigned to a satellite peak. ${ }^{[26,27]} \mathrm{A}$ small amount of oxygen has also been detected, as residues from the oxygen-containing resin precursor after pyrolysis. The areal distribution of these elements in Fe-N-G-HPC nanocomposite was further mapped by energy dispersive spectroscopy (EDS), as shown in Figure $3 \mathrm{~b}$ and $\mathrm{S7}$. Apart from the rich $\mathrm{C}$ element, $\mathrm{Fe}$ and $\mathrm{N}$ elements are also found to be finely dispersed all over the material on both the porous carbon and graphene regions, even at the places where no $\mathrm{Fe}$ or its oxide particles could be seen. These highly dispersed $\mathrm{Fe}$ and $\mathrm{N}$ elements throughout the carbon framework suggest that these elements have been evenly decorated on the materials at atomic scale. This feature is highly desirable for $\mathrm{Fe}-\mathrm{N}-\mathrm{C}$ materials to form the expected Fe-N active sites for ORR. 
a)

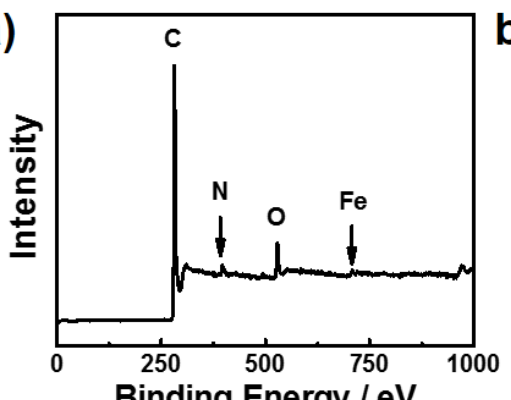

Binding Energy / eV

c)

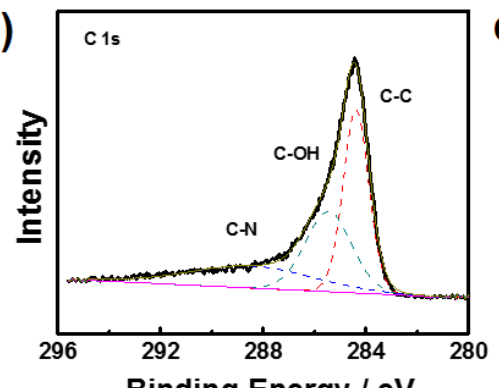

e)

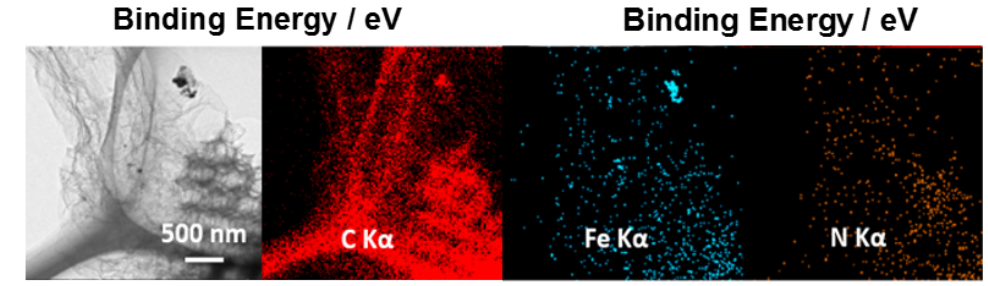

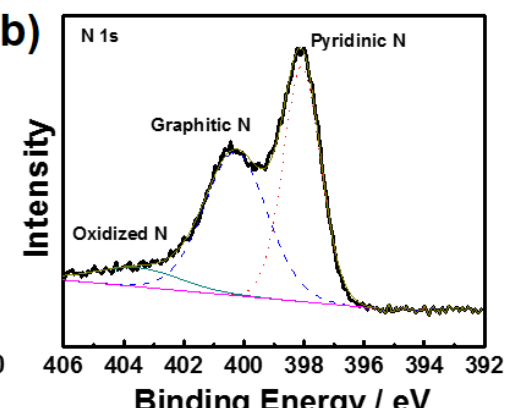

d)

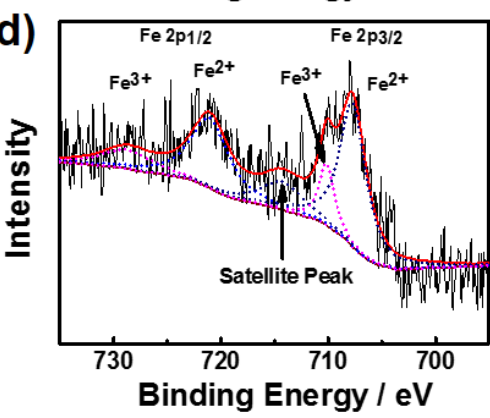

Figure 3. (a-d) XPS spectrum of the survey scan, C 1s, N 1s, and Fe 2p, respectively, (e) elemental mapping by EDS.

Besides, a small amount of $\mathrm{Fe}$ and $\mathrm{Fe}_{3} \mathrm{O}_{4}$ particles (as confirmed by XRD) of tens of nanometers could also be very occasionally observed on the HPC and graphene sections on the material (Figure S3 and 4a). This could be a result of the relocation and aggregation of metal species during annealing at high temperatures. However, the amount of Fe aggregations is much smaller as compared to previous reports on Fe-N-C hybrids. ${ }^{[12,15,23]}$ 
a)

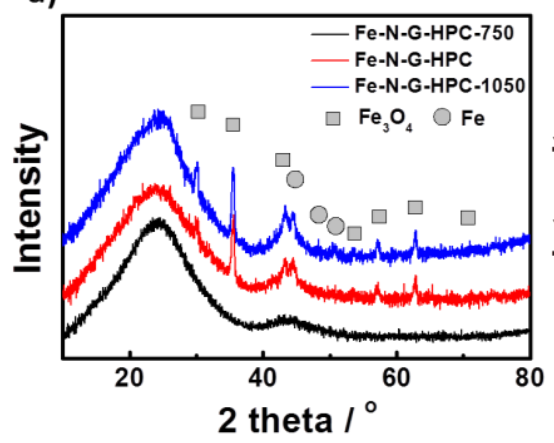

b)

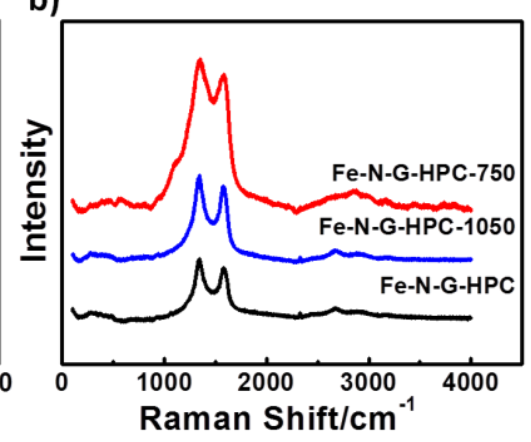

Figure 4. (a) XRD and (b) Raman curves of Fe-N-G-HPC heated at different temperature

Raman spectra of the samples were also collected to assess their graphitic structure further, as shown in Figure $4 \mathrm{~b}$. The $\mathrm{G}\left(1585 \mathrm{~cm}^{-1}\right)$ and $\mathrm{D}\left(1350 \mathrm{~cm}^{-1}\right)$ bands, which represent the hexagonally bonded carbon atoms inside the graphitic network and the distorted carbon frames on the defect sites, respectively, were observed on the spectra. The D peak arises from a disorder-induced vibration mode of graphene layers in the carbon phase, linked to the breathing motion of $\mathrm{sp}^{2}$-rings, while the $\mathrm{G}$ mode results from an in-plane bond stretching of $\mathrm{sp}^{2}$-hybridized carbon atoms. For the sample of Fe-N-G-HPC-750, these two bands become significantly slimmer. The $\mathrm{I}_{\mathrm{G}} / \mathrm{I}_{\mathrm{D}}$ ratio increases when the sample is heated at a higher temperature, indicating a more completed graphitic structure was formed. On the contrary, the Fe-N-G-HPC, although also heated up to $900{ }^{\circ} \mathrm{C}$, gives broader bands at these positions, suggesting its more amorphous nature with lower graphitization and larger amount of distortions, in agreement with XRD results (Figure 4a).

To evaluate the ORR catalytic performance of the materials and to confirm the advantage of the in-situ formed 3D inter-connected graphene network in promoting 
the catalytic ORR, Fe-N-G-HPC and Fe-N-HPC were firstly compared by cyclic voltammetry $(\mathrm{CV}) \mathrm{O}_{2}$-saturated $0.1 \mathrm{M} \mathrm{KOH}$ electrolyte (Figure 5a). Both samples give pronounced ORR response upon the introduction of oxygen into the electrolyte, revealing their ability to electrochemically reduce $\mathrm{O}_{2}$. Noticeably, the ORR peak position of Fe-N-G-HPC $(-0.21 \mathrm{~V})$ is more positive than the Fe-N-HPC sample $(-0.29$ V). This suggests that $\mathrm{O}_{2}$ can be more effectively reduced on Fe-N-G-HPC composite at a smaller overpotential, indicating the better ORR catalytic activity on the Fe-N-G-HPC than on the Fe-N-HPC.
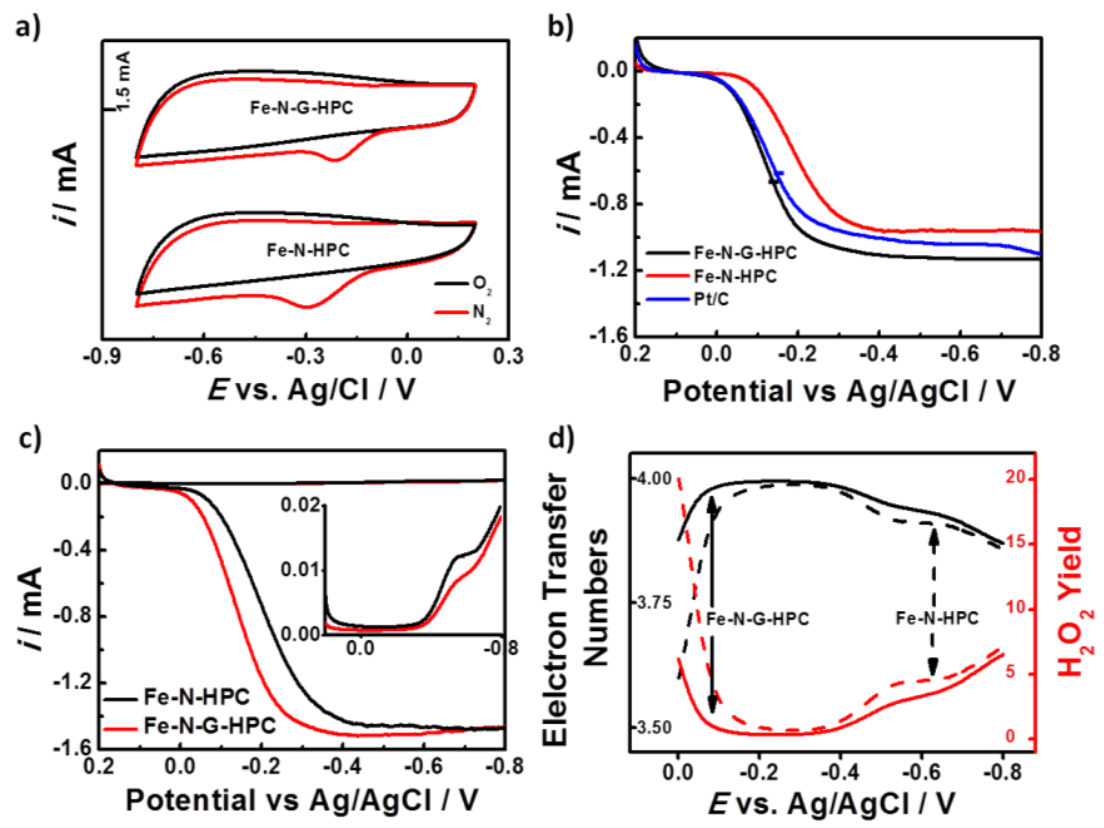

Figure 5. Electrocatalytic performance for ORR of the Fe-N-G-HPC and Fe-N-HPC samples in comparison with the commercial Pt/C. (a) $\mathrm{CV}$ collected in $\mathrm{N}_{2}$ or $\mathrm{O}_{2}$-saturated electrolyte, (b) LSV-RDE and (c) LSV-RRDE of the samples, with ring currents in the inset, and (d) the electron transfer numbers and the peroxide production of the samples. 
For a deeper insight into the ORR process over the electrocatalysts, the materials were then assessed by LSV on an RDE in comparison to an identical amount of commercial $20 \mathrm{wt} . \% \mathrm{Pt} / \mathrm{C}$ catalyst, as shown in Figure 5b and S8 a-c. All the samples reach the diffusion limiting region (i.e., the plateau on the LSV curve) before $-0.3 \mathrm{~V}$ with a similar plateau current, suggesting the ORR kinetics are quite facile. Half-wave potential $\left(\mathrm{E}_{1 / 2}\right)$ has been adopted to compare the activity of the materials. The Fe-N-G-HPC nanocomposite gave the most positive $\mathrm{E}_{1 / 2}$ value that is $c a .28 \mathrm{mV}$ more positive than the $\mathrm{Pt} / \mathrm{C}$, clearly showing the highest catalytic activity for ORR of the Fe-N-G-HPC material.

Moreover, the ORR efficiency of the catalysts was measured using an RRDE. In Figure 5c, apart from the more positive ORR onset potential of $\mathrm{Fe}-\mathrm{N}-\mathrm{G}-\mathrm{HPC}$ as obtained from the RDE test, this material also possesses a larger ORR current in the low overpotential region between 0 to $-0.4 \mathrm{~V}$ and a very low ring electrode current, in comparison to the Fe-N-HPC. As a result, the average number of electrons transferred $(n)$ in the ORR over Fe-N-G-HPC in this region is much higher (up to 3.99) than that of the Fe-N-HPC. Likewise, the less production of peroxide $(<1 \%$ at $-0.1 \mathrm{~V})$ further suggests the higher efficiency of the ORR process on the Fe-N-G-HPC (Figure 5d). Overall, the ORR over Fe-N-G-HPC nanocomposite undergoes an efficient one-step and four-electron pathway, which is remarkably superior to its Fe-N-HPC counterpart and clearly demonstrates the importance of in-situ formed conductive graphene in uplifting its ORR performance. ${ }^{[14]}$ The Fe-N-G-HPC catalyst exhibited better ORR activity compared with those reported in the literature, regarding the half-wave 
potential and electron transfer number $(n)$ (Table S2). Moreover, we have then conducted the stability test of the material. After the chronoamperometry test at -0.2 $\mathrm{V}$ vs. $\mathrm{Ag} / \mathrm{AgCl}$ for $10 \mathrm{~h}$ (Figure $\mathrm{S} 8 \mathrm{~d}$ ), only a very slight catalytic fading of $\sim 11.36 \%$ occurred, which is better than the previous results in the same testing condition. ${ }^{[15]}$

Due to the versatility of this protocol in tuning the composition of these hierarchical porous and carbon-based materials, we have also developed a series of HPC analogs with selected heteroelements (denoted as Fe-HPC and N-HPC) and similar hierarchical structures as the Fe-N-HPC, to gain better insight on the roles of the decorated $\mathrm{Fe}$ and $\mathrm{N}$ elements in the catalysts.

Their ORR performances were evaluated by CV and LSV methods in comparison to that of the Fe-N-HPC nanocomposite (Figure 6a, S9, and S10). Compared with the pristine HPC, both Fe-HPC and N-HPC show better performances. This suggests that $\mathrm{Fe}$ and $\mathrm{N}$ doped carbons are more active for the ORR than pure carbon, which is consistent with the other recent reports. Interestingly, the Fe-HPC was found to deliver a relatively better catalytic activity than the N-HPC as given by the more positive ORR onset potential and the larger Faradaic current.

When both Fe and N species are introduced to HPC, the Fe-N-HPC sample could exhibit a more positive ORR onset potential $(-0.07 \mathrm{~V})$ than the single-element doped ones (i.e., $0.12 \mathrm{~V}$ for $\mathrm{Fe}-\mathrm{HPC}$ and $-0.14 \mathrm{~V}$ for $\mathrm{N}-\mathrm{HPC}$ ). Moreover, the Fe-N-HPC quickly reached its diffusion-limiting current ( $c a .-0.4$ to $-0.8 \mathrm{~V}$ ) soon after the kinetic regime ( $c a$. 0 to $-0.4 \mathrm{~V}$ ). This indicates a rapid activation of the ORR process. In contrast, the analogs (i.e., Fe-HPC, N-HPC or HPC) do not reach a current plateau in 
the same potential region, which suggests that the ORR is yet to reach a complete four-electron process at this stage. ${ }^{8,21}$ The better ORR efficiency of Fe-N impregnated catalyst was further confirmed by its larger electron transfer number and lower peroxide production at low overpotential as shown in Figure $6 \mathrm{~b}$ and S11. From these observations and comparison, it is thus reasonable to conclude that $\mathrm{Fe}$ and $\mathrm{N}$ species in the carbon material can synergistically boost the ORR activity and enhance the ORR efficiency from a two-electron pathway to a four-electron pathway, especially at low overpotential region. This endorses the collaborative role of the $\mathrm{Fe}$ and $\mathrm{N}$ species in delivering an efficient ORR. ${ }^{[28,29]}$

Pyrolysis temperature in the catalyst preparation is another important parameter that can alter the chemical composition, microstructure, as well as the related catalytic behavior of the catalyst. We have fabricated the $\mathrm{Fe}-\mathrm{N}$ decorated hybrid carbon materials at 750 and $1050{ }^{\circ} \mathrm{C}$ (denoted as Fe-N-G-HPC-750 and Fe-N-G-HPC-1050) to study the effect of temperature. Their ORR catalytic activity was evaluated and compared with the Fe-N-G-HPC prepared at $900{ }^{\circ} \mathrm{C}$ (Figure $6 \mathrm{c}$, d, and S12).

It is interesting to note that the sample prepared at $900{ }^{\circ} \mathrm{C}$ gives the best ORR performance, although it is only slightly better than the one synthesized at $1050{ }^{\circ} \mathrm{C}$ (Figure 6c). In contrast, the sample fabricated at $750{ }^{\circ} \mathrm{C}$ shows a poor ORR activity with an over $100 \mathrm{mV}$ more negative onset potential. On the other hand, although all the samples can eventually reach high ORR efficiency by giving high electron transfer numbers and low peroxide production when the potential goes negative enough (e.g., over $-0.2 \mathrm{~V}$ for the Fe-N-G-HPC sample), the samples prepared at higher 
temperatures show substantially higher ORR efficiency at the low over-potential between 0 to $-0.05 \mathrm{~V}$ (Figure $6 \mathrm{~d}$ ). Thus, high-temperature treatment can remarkably improve the materials' ORR performance at the low over-potential region, which is the key factor to evaluate the activity of an ORR catalyst.
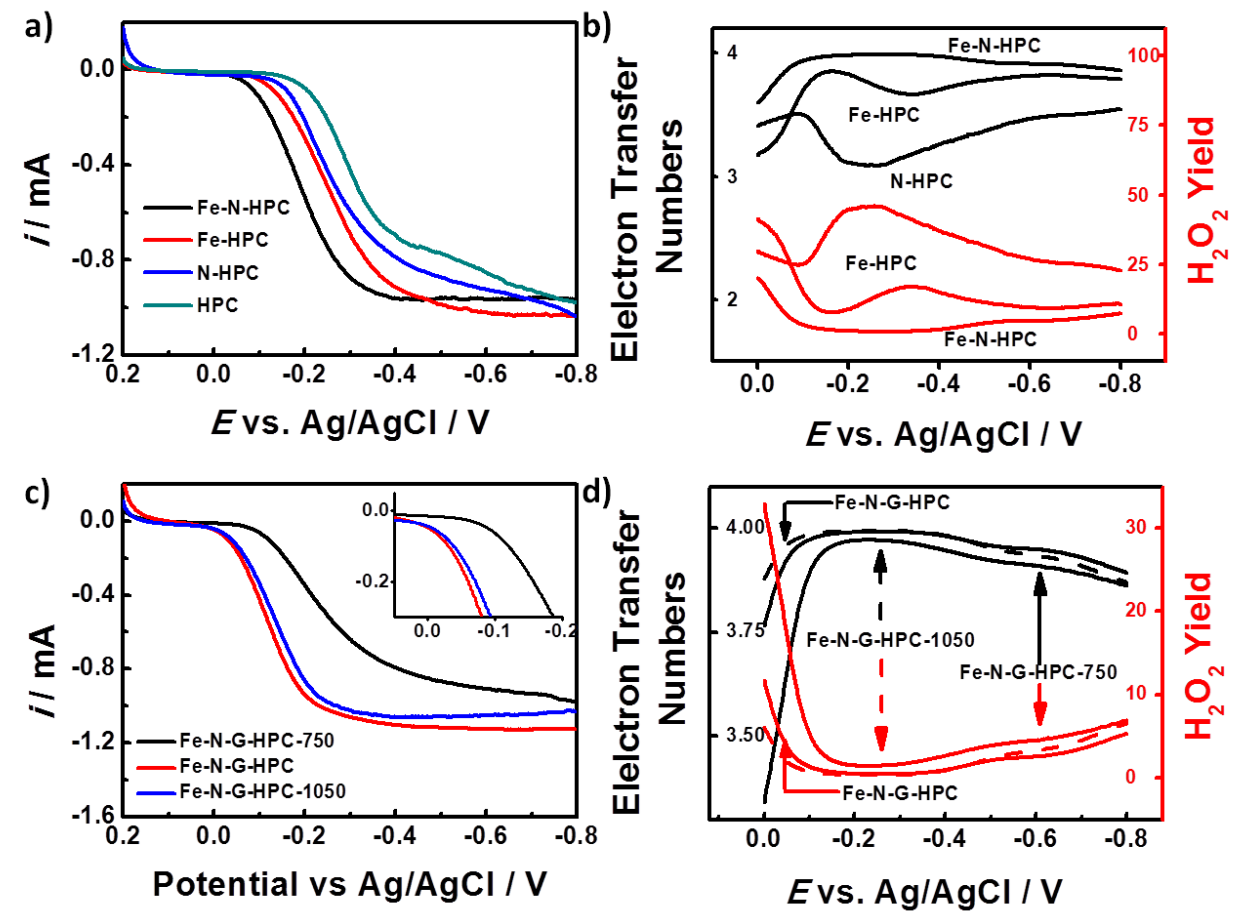

Figure 6. Electrocatalytic performance for the ORR of the analogs. (a) LSV-RDE of the analogs and (b) the corresponding $\mathrm{n}$ number and peroxide production profile along the reaction potentials. (c) LSV-RDE of the Fe-N-G-HPC composite and the thermally treated derivatives at different temperatures; the inset shows the enlarged onset potential section. (d) The corresponding electron transfer numbers and peroxide production of the composite and the derivatives.

The best performance of Fe-N-G-HPC catalyst synthesized at $900{ }^{\circ} \mathrm{C}$ can be attributed to the combination of compositional and structural aspects. Compared with the Fe-N-G-HPC-750 $\left(691 \mathrm{~m}^{2} \mathrm{~g}^{-1}\right)$, the samples prepared at $900{ }^{\circ} \mathrm{C}$ and $1050{ }^{\circ} \mathrm{C}$ 
possessed a larger specific surface area (1144 and $1233 \mathrm{~m}^{2} \mathrm{~g}^{-1}$, respectively) that can be mainly attributed to the mesopores (Figure S13). This would help expose more active sites on the Fe-N-G-HPC and Fe-N-G-HPC-1050 samples, while the much smaller surface area of the Fe-N-G-HPC-750 sample may come from the pore blockage possibly by the residual nitrides in the material as well as the lower carbonization degree at this temperature.

The chemical composition of the samples was also characterized by XPS (Figure S14). It is interesting to find that Fe-N-G-HPC-750 possesses the highest content of Fe and $\mathrm{N}$ (0.38 and 11.92 at.\%, respectively), which is much higher than those of Fe-N-G-HPC (0.15 and 2.40 at.\% ) and Fe-N-G-HPC-1050 (0.09 and 1.68 at.\%). This suggests the possible existence of the undecomposed $\mathrm{g}-\mathrm{C}_{3} \mathrm{~N}_{4}$ on this material. However, the proportion of ORR-active graphitic nitrogen increases while the preparation temperature rises from $750{ }^{\circ} \mathrm{C}$ to $1050{ }^{\circ} \mathrm{C}$ (Table S3), and thus the Fe-N-G-HPC-750 sample contains a very large amount of less active pyridinic nitrogen atoms in its carbon framework. ${ }^{[30]}$ As a result, the poor performance of the Fe-N-G-HPC-750 could be a mixed result of both the low surface area and the low amount of the active $\mathrm{N}$ species in the material. On the other hand, the samples prepared at $900{ }^{\circ} \mathrm{C}$ and $1050{ }^{\circ} \mathrm{C}$ have a large surface area and a high content of active $\mathrm{N}$ species. The slightly better performance of the Fe-N-G-HPC sample synthesized at $900{ }^{\circ} \mathrm{C}$ can be attributed to its higher amount of the $\mathrm{Fe}$ and active $\mathrm{N}$ species in the material.

\section{Conclusion}


To sum up, we have designed and fabricated a Fe-N doped modified hierarchical porous carbon in a nanocomposite hybrid with an in-situ grown graphene layer. The nanocomposite exhibited an outstanding ORR catalytic activity even better than a commercial Pt/C catalyst. Moreover, a series of HPC analogs with controlled chemical composition and microstructure were investigated to reveal the origin of ORR activity. The roles of $\mathrm{Fe}$ and $\mathrm{N}$ species on the carbon surface in promoting the ORR were studied and both appeared to be the key elements for the activity improvement. We anticipate that the finding could shed light on the design of other materials structural carbon materials for electrochemical catalysis.

\section{Acknowledgments}

This work is financially supported by Australian Research Council under the Discovery Early Career Researcher Award (DECRA, No. DE170100871) scheme and China Scholarship Council (No. 201804910018). 


\section{References}

[1] Steele B C H, Heinzel A, Materials For Fuel-cell Technologies, Nature 2001; 414(6861):345-52.

[2] Débart A, Paterson A J, Bao J, Bruce P G, $\alpha-\mathrm{MnO}_{2}$ Nanowires: A Catalyst for the $\mathrm{O}_{2}$ Electrode in Rechargeable Lithium Batteries, Angew Chem Int Edit 2008; 47(24):4521-4.

[3] Gong K, Du F, Xia Z, Durstock M, Dai L, Nitrogen-Doped Carbon Nanotube Arrays with High Electrocatalytic Activity for Oxygen Reduction, Science 2009; 323(5915):760-4.

[4] Wang S, Zhang L, Xia Z, Roy A, Chang D W, Baek J B, Dai L, BCN Graphene as Efficient Metal-Free Electrocatalyst for the Oxygen Reduction Reaction, Angew Chem Int Edit 2012; 51(17):4209-12.

[5] Chen P, Xiao $\mathrm{T} \mathrm{Y}$, Qian $\mathrm{Y} \mathrm{H}$, Li S S, Yu S H, A Nitrogen-Doped Graphene/Carbon Nanotube Nanocomposite with Synergistically Enhanced Electrochemical Activity, Adv Mater 2013; 25(23):3192-6.

[6] Liang J, Jiao Y, Jaroniec M, Qiao S Z, Sulfur and Nitrogen Dual-Doped Mesoporous Graphene Electrocatalyst for Oxygen Reduction with Synergistically Enhanced Performance, Angew Chem Int Edit 2012; 51(46):11496-500.

[7] Jeon I Y, Zhang S, Zhang L, Choi H J, Seo J M, Xia Z, Dai L, Baek J B, Edge-Selectively Sulfurized Graphene Nanoplatelets as Efficient Metal-Free Electrocatalysts for Oxygen Reduction Reaction: The Electron Spin Effect, Adv Mater 2013; 25(42):6138-45.

[8] Liang J, Zheng Y, Chen J, Liu J, Hulicova-Jurcakova D, Jaroniec M, Qiao S Z, Facile Oxygen Reduction on a Three-Dimensionally Ordered Macroporous Graphitic $\mathrm{C}_{3} \mathrm{~N}_{4} /$ Carbon Composite Electrocatalyst, Angew Chem Int Edit 2012; 51(16):3892-6.

[9] Wu Z S, Yang S, Sun Y, Parvez K, Feng X, Mullen K, 3D Nitrogen-Doped Graphene Aerogel-Supported $\mathrm{Fe}_{3} \mathrm{O}_{4}$ Nanoparticles as Efficient Electrocatalysts for the Oxygen Reduction Reaction, J Am Chem Soc 2012; 134(22):9082-5.

[10] Xiang Z, Xue Y, Cao D, Huang L, Chen J, Dai L, Highly Efficient Electrocatalysts for Oxygen Reduction Based on 2D Covalent Organic Polymers Complexed with Non-precious Metals, Angew Chem Int Edit 2014; 53(9):2433-7.

[11] Liang $\mathrm{H} \mathrm{W}$, Wei $\mathrm{W}$, Wu Z S, Feng X, Mullen K, Mesoporous Metal-Nitrogen-Doped Carbon Electrocatalysts for Highly Efficient Oxygen Reduction Reaction, J Am Chem Soc 2013; 135(43):16002-5.

[12] Chung $\mathrm{H}$ T, Won J H, Zelenay P, Active and Stable Carbon Nanotube/Nnanoparticle Composite Electrocatalyst for Oxygen Reduction, Nat Commun 2013; 4:1922.

[13] Zhang G, Xia B Y, Wang X, Lou X W, Strongly Coupled $\mathrm{NiCo}_{2} \mathrm{O}_{4}-\mathrm{rGO}$ Hybrid Nanosheets as a Methanol-Tolerant Electrocatalyst for the Oxygen Reduction Reaction, Adv Mater 2013; 26(15):2408-12.

[14] Liang J, Du X, Gibson C, Du X W, Qiao S Z, N-Doped Graphene Natively Grown on Hierarchical Ordered Porous Carbon for Enhanced Oxygen Reduction, Adv Mater 2013; 25(43):6226-31. 
[15] Liang J, Zhou R F, Chen X M, Tang Y H, Qiao S Z, Fe-N Decorated Hybrids of CNTs Grown on Hierarchically Porous Carbon for High-Performance Oxygen Reduction, Adv Mater 2014; 26(35):6074-9.

[16] Guan B Y, Lu Y, Wang Y, Wu M, Lou X W, Porous Iron-Cobalt Alloy/Nitrogen-Doped Carbon Cages Synthesized via Pyrolysis of Complex Metal-Organic Framework Hybrids for Oxygen Reduction, Adv Funct Mater 2018; 28(10):1706738.

[17] Zhang H, Zhou W, Chen T, Guan B Y, Li Z, Lou X W, A Modular Strategy for Decorating Isolated Cobalt Atoms into Multichannel Carbon Matrix for Electrocatalytic Oxygen Reduction, Energ Environ Sci 2018; 11(8):1980-4.

[18] Chung H T, Cullen D A, Higgins D, Sneed B T, Holby E F, More K L, Zelenay P, Direct Atomic-Level Insight into The Active Sites of a High-performance PGM-free ORR Catalyst, Science 2017; 357(6350):479-84.

[19] Yang H B, Miao J, Hung S-F, Chen J, Tao H B, Wang X, Zhang L, Chen R, Gao J, Chen H M, Dai L, Liu B, Identification of Catalytic Sites for Oxygen Reduction and Oxygen Evolution in N-Doped Graphene Materials: Development of Highly Efficient Metal-free Bifunctional Electrocatalyst, Sci Adv 2016; 2(4):e1501122.

[20] Kramm U I, Herrmann-Geppert I, Behrends J, Lips K, Fiechter S, Bogdanoff P, On an Easy Way To Prepare Metal-Nitrogen Doped Carbon with Exclusive Presence of $\mathrm{MeN}_{4}$-type Sites Active for the ORR, J Am Chem Soc 2016; 138(2):635-40.

[21] Zhu Q-L, Xia W, Zheng L-R, Zou R, Liu Z, Xu Q, Atomically Dispersed $\mathrm{Fe} / \mathrm{N}$-doped Hierarchical Carbon Architectures Derived from a Metal-Organic Framework Composite for Extremely Efficient Electrocatalysis, ACS Energy Lett 2017; 2(2):504-11.

[22] Wen Z, Ci S, Zhang F, Feng X, Cui S, Mao S, Luo S, He Z, Chen J, Nitrogen-Enriched Core-Shell Structured $\mathrm{Fe} / \mathrm{Fe}_{3} \mathrm{C}-\mathrm{C}$ Nanorods as Advanced Electrocatalysts for Oxygen Reduction Reaction, Adv Mater 2014; 24(11):1399-404.

[23] Lee J S, Park G S, Kim S T, Liu M, Cho J, A Highly Efficient Electrocatalyst for the Oxygen Reduction Reaction: N-Doped Ketjenblack Incorporated into $\mathrm{Fe} / \mathrm{Fe}_{3} \mathrm{C}$-Functionalized Melamine Foam, Angew Chem Int Edit 2012; 52(3):1026-30. [24] Hu Y, Jensen J O, Zhang W, Cleemann L N, Xing W, Bjerrum N J, Li Q, Hollow Spheres of Iron Carbide Nanoparticles Encased in Graphite Layers as Oxygen Reduction Catalysts, Angew Chem Int Edit 2014; 53(14):3675-9.

[25] Deng D, Yu L, Chen X, Wang G, Jin L, Pan X, Deng J, Sun G, Bao X, Iron Encapsulated within Pod-like Carbon Nanotubes for Oxygen Reduction Reaction, Angew Chem Int Edit 2013; 52(1):371-5.

[26] Lin L, Zhu Q, Xu A-W, Noble-Metal-Free Fe-N/C Catalyst for Highly Efficient Oxygen Reduction Reaction under Both Alkaline and Acidic Conditions, J Am Chem Soc 2014; 136(31):11027-33.

[27] Ahn S H, Yu X, Manthiram A, "Wiring" Fe- $\mathrm{N}_{\mathrm{x}}$-Embedded Porous Carbon Framework onto 1D Nanotubes for Efficient Oxygen Reduction Reaction in Alkaline and Acidic Media, Adv Mater 2017; 29(26):1606534.

[28] Wei J, Liang Y, Hu Y, Kong B, Simon G P, Zhang J, Jiang S P, Wang H, A Versatile Iron-Tannin-Framework Ink Coating Strategy to Fabricate Biomass-Derived 
Iron Carbide/Fe-N-Carbon Catalysts for Efficient Oxygen Reduction, Angew Chem Int Edit 2016; 128(4):1377-81.

[29] Meng F-L, Wang Z-L, Zhong H-X, Wang J, Yan J-M, Zhang X-B, Reactive Multifunctional Template-Induced Preparation of Fe-N-Doped Mesoporous Carbon Microspheres Towards Highly Efficient Electrocatalysts for Oxygen Reduction, Adv Mater 2016; 28(36):7948-55.

[30] Yang S B, Feng X L, Wang X C, Mullen K, Graphene-Based Carbon Nitride Nanosheets as Efficient Metal-Free Electrocatalysts for Oxygen Reduction Reactions, Angew Chem Int Edit 2011; 50(23):5339-43. 


\section{Supplementary Information}
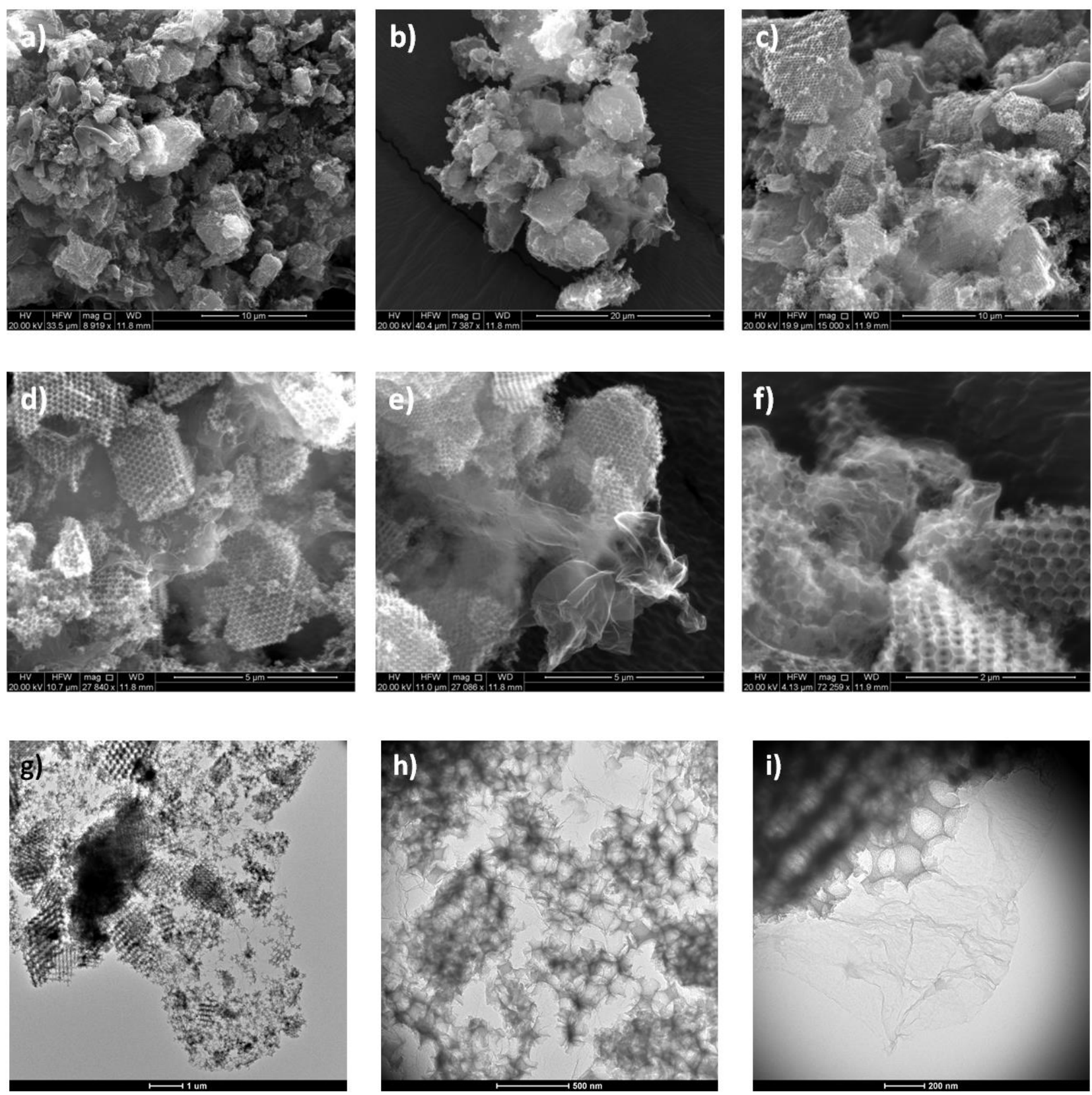

Figure S1. (a-f) SEM and (g-i) TEM images of Fe-N-G-HPC at different magnifications. 

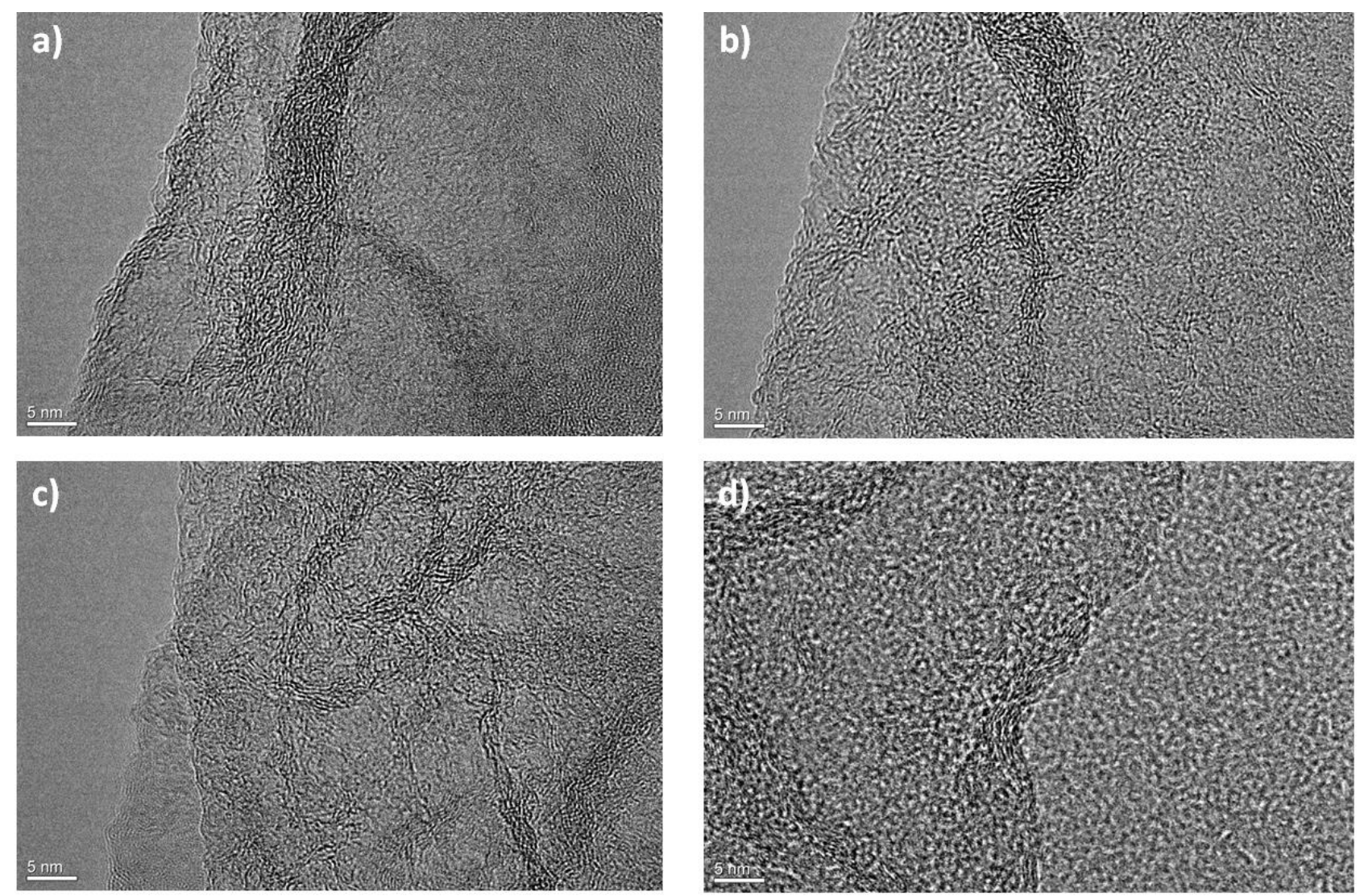

Figure S2. High resolution TEM images of the graphene in the Fe-N-G-HPC material. 

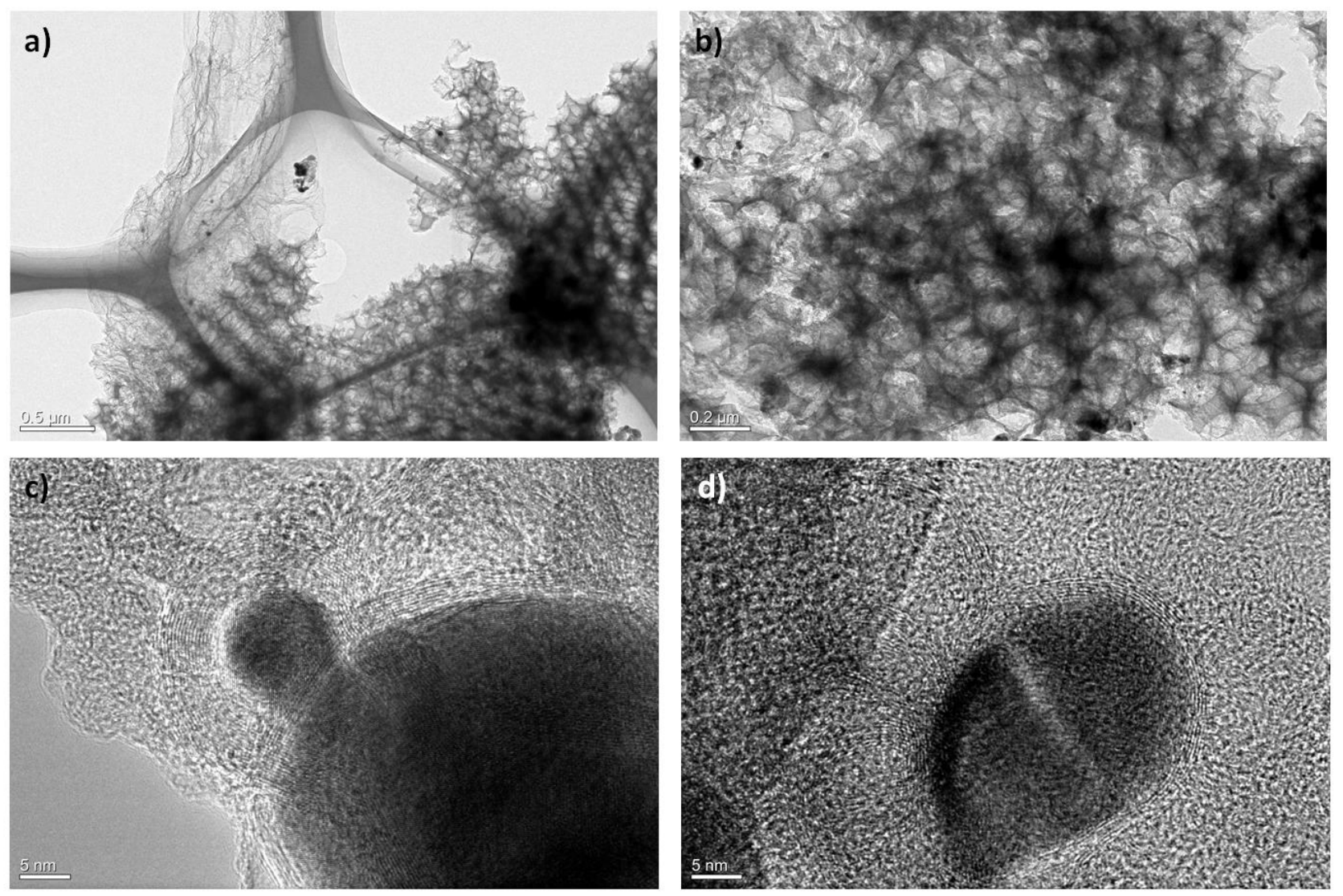

Figure S3. TEM images showing the iron (oxide) nanoparticles on the Fe-N-G-HPC sample. 

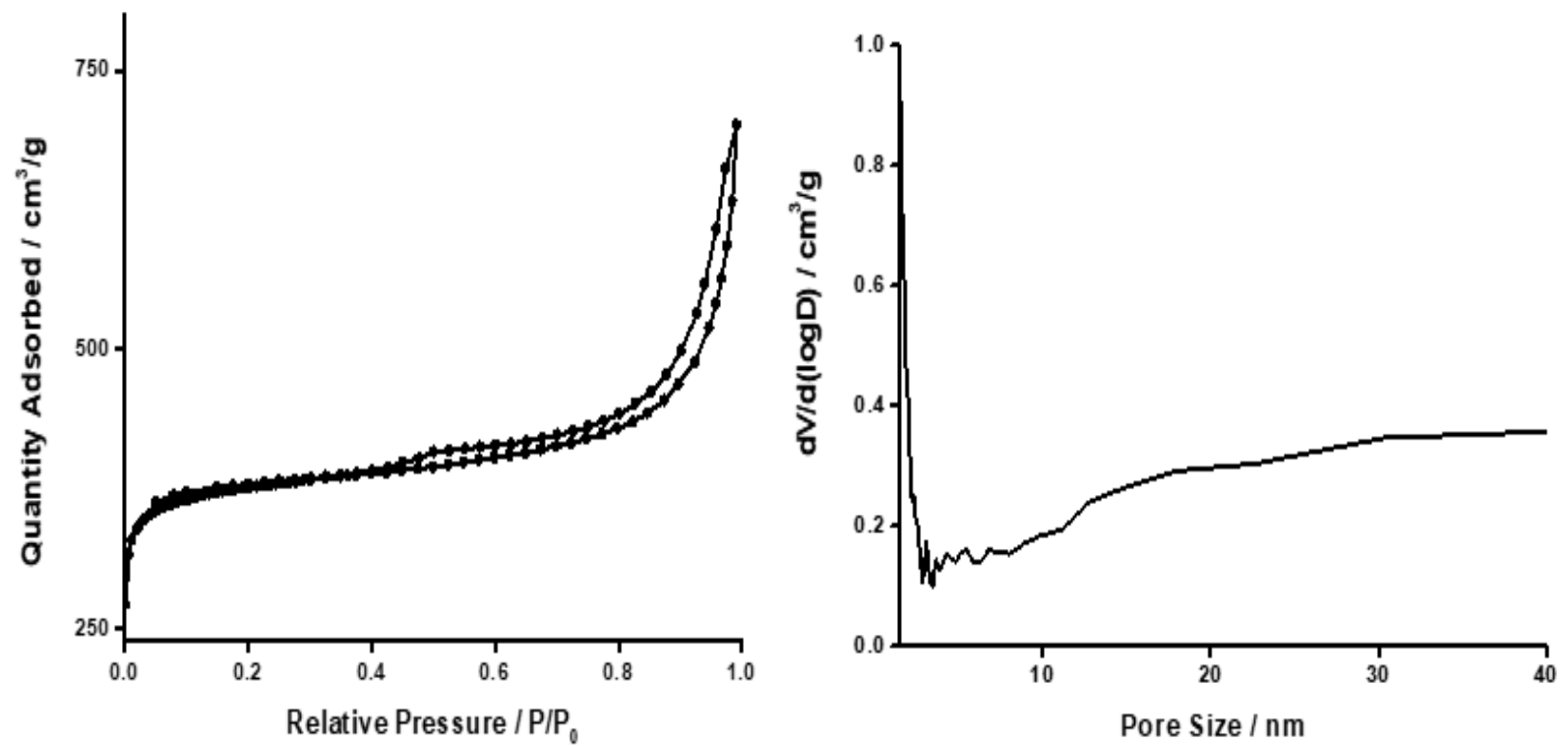

Figure S4. (a) Nitrogen adsorption-desorption isotherms of Fe-N-HPC and (b) the corresponding pore size distribution.
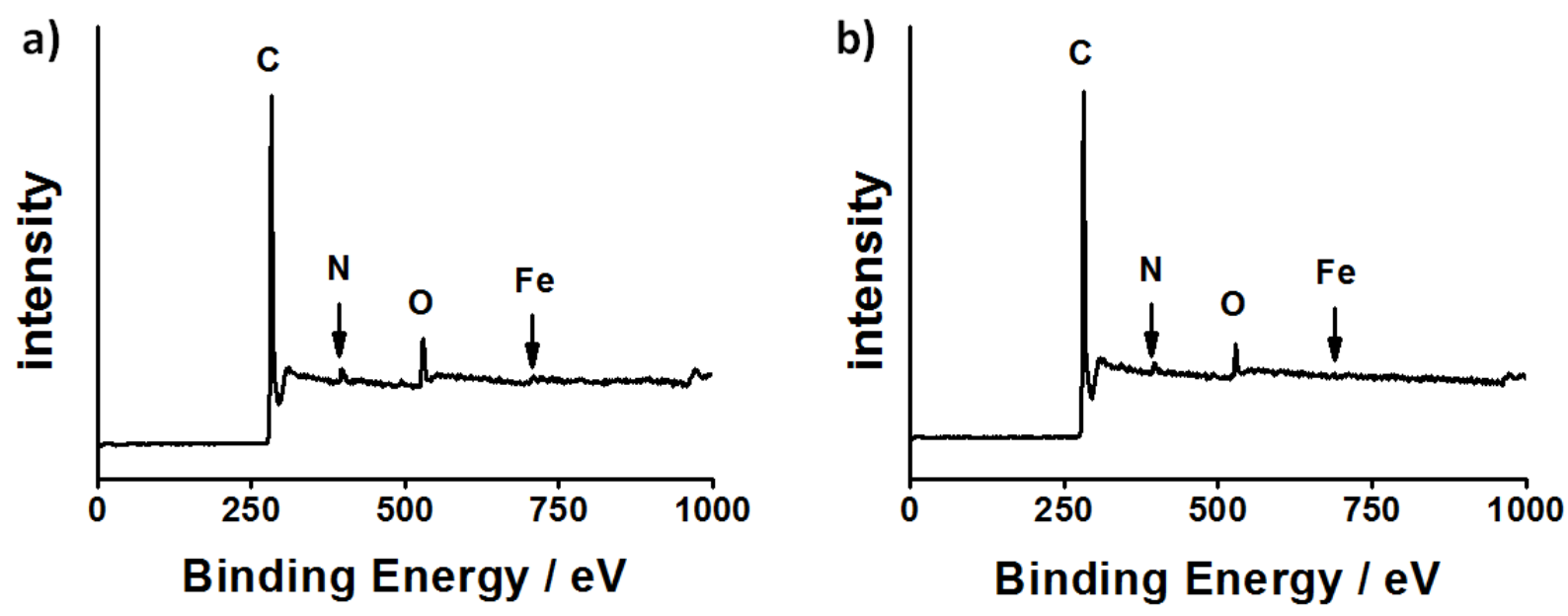

Figure S5. XPS survey scans of (a) Fe-N-G-HPC and (b) Fe-N-HPC. 
(a)
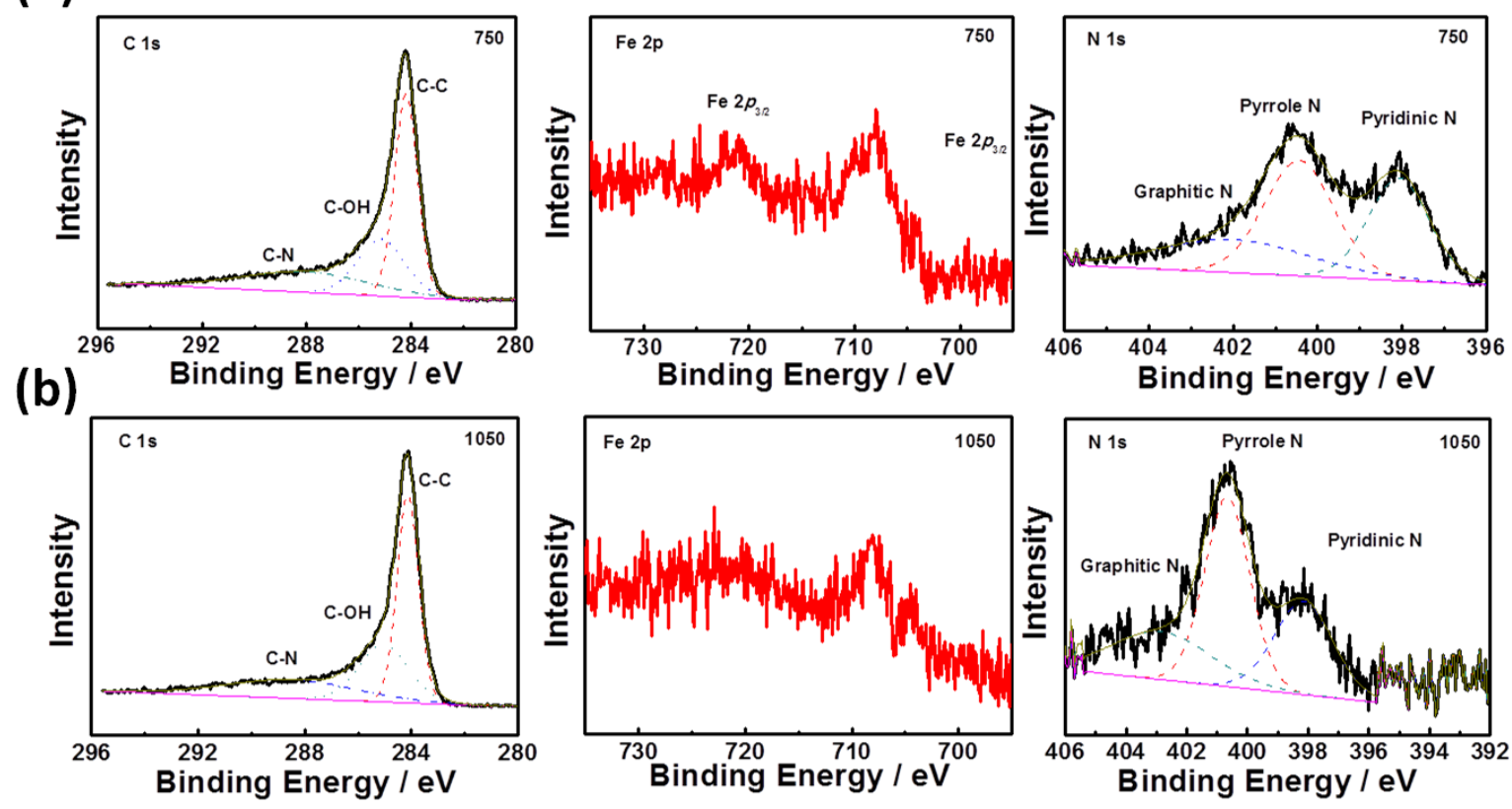

Figure S6. High resolution N1s, C1s and Fe 2p spectrum of (a) Fe-N-G-HPC-750 and (c) Fe-N-G-HPC1050.

Table S1. The content of different elements in the Fe-N-G-HPC and Fe-N-HPC samples obtained from the XPS results in Figure S6.

\begin{tabular}{ccccc}
\hline Content (at.\%) & Fe & N & O & C \\
\hline Fe-N-HPC & 0.14 & 2.11 & 3.29 & 94.46 \\
Fe-N-G-HPC & 0.15 & 2.40 & 5.43 & 92.01 \\
\hline
\end{tabular}



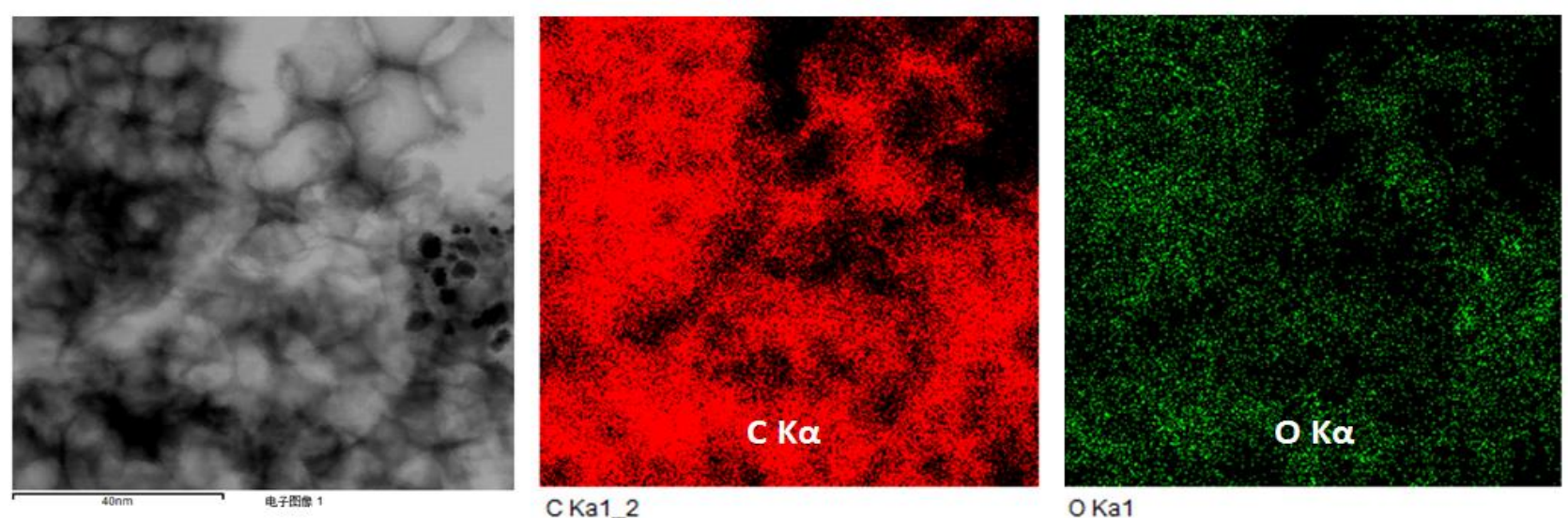

CKa1_2

O Ka1
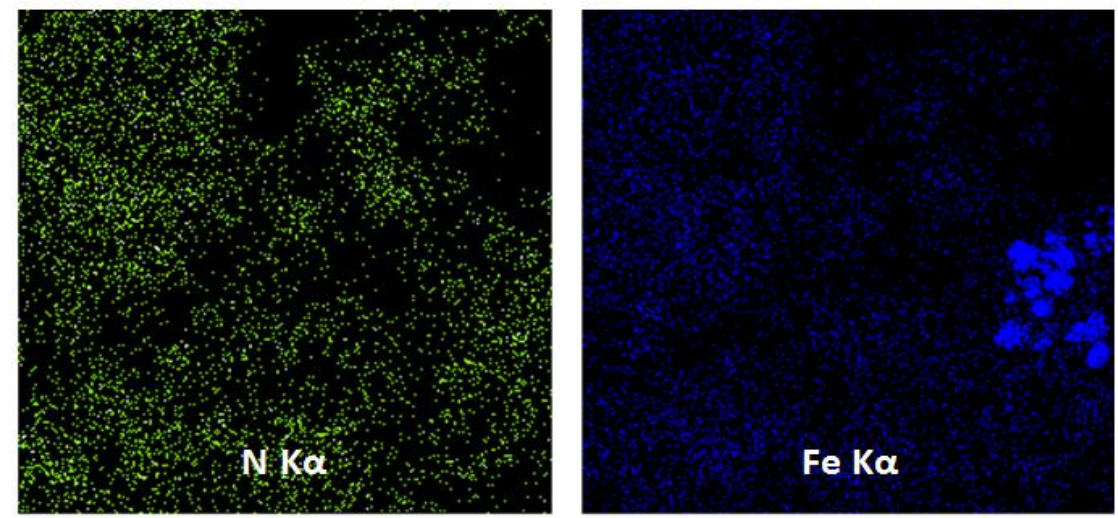

N Ka1_2

\section{Fe Ka1}
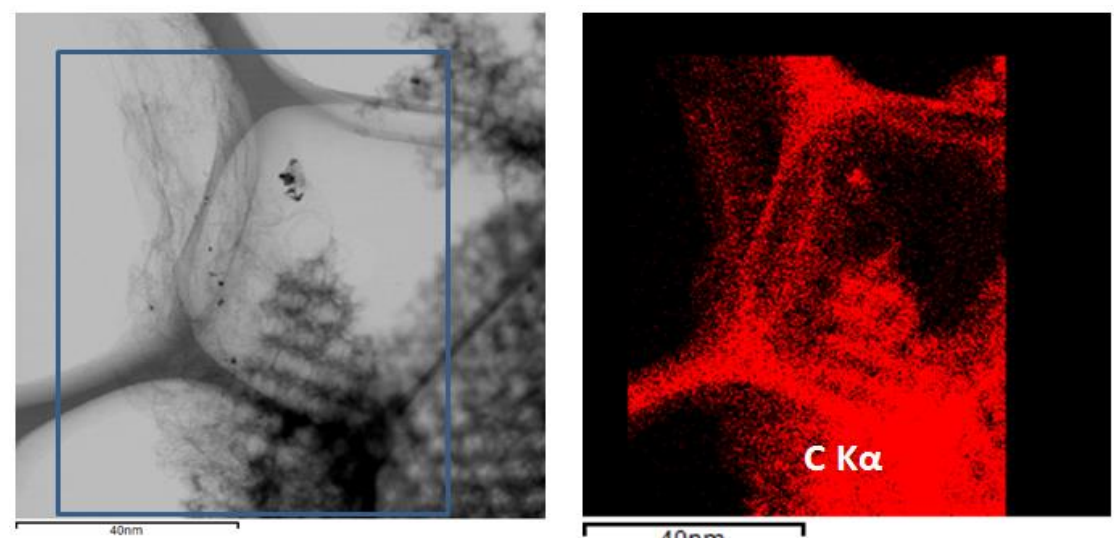

$40 \mathrm{~nm}$

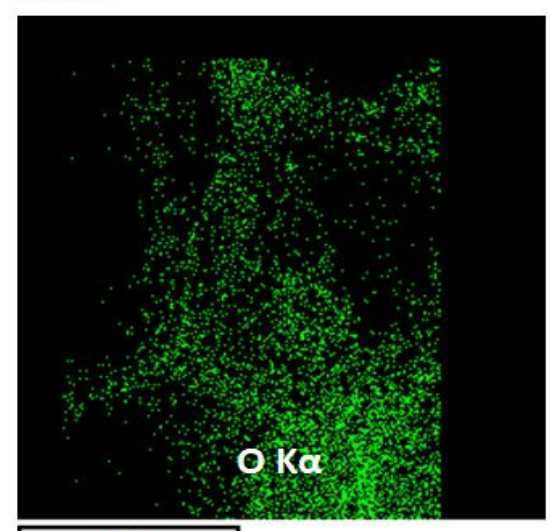

$40 \mathrm{~nm}$
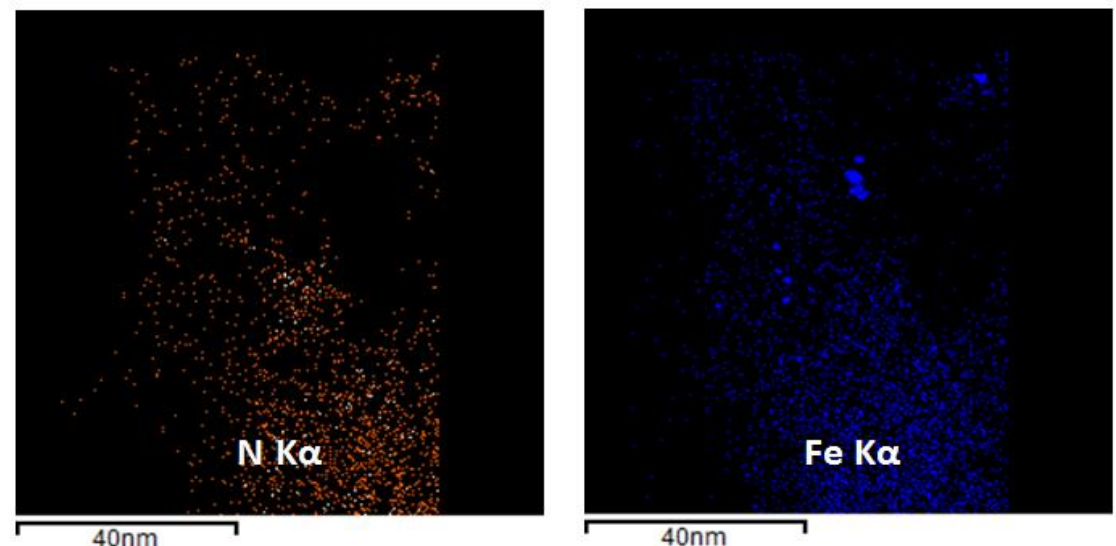

Figure S7. Elemental mappings of two regions in a Fe-N-G-HPC sample. 

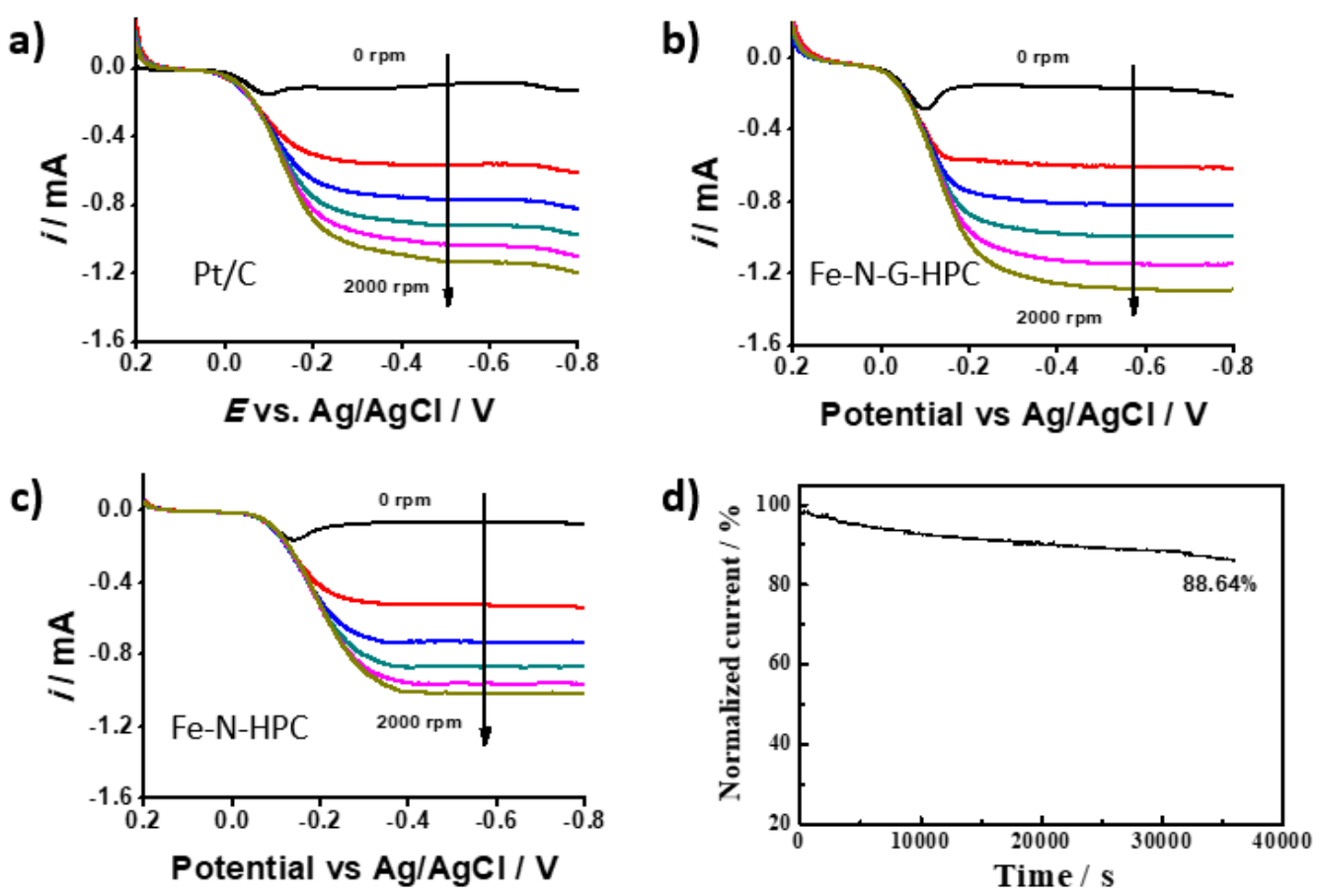

Figure S8. RDE voltammograms of (a) Pt/C, (b) Fe-N-G-HPC and (c) Fe-N-HPC samples obtained at different rotating speeds. (d) Chronoamperometry test of the Fe-N-G-HPC catalyst at $-0.2 \mathrm{~V}$ vs. $\mathrm{Ag} / \mathrm{AgCl}$ for $10 \mathrm{~h}$.

Table S2. Comparation of reported ORR performance for Fe-N-C catalysts in $0.1 \mathrm{M}$ KOH solution.

\begin{tabular}{|c|c|c|c|c|}
\hline \multirow{2}{*}{ Electrocatalyst } & \multicolumn{2}{|c|}{$\mathrm{E}_{1 / 2}(\mathrm{~V})$} & \multirow{2}{*}{$n$} & \multirow{2}{*}{ Ref } \\
\hline & vs $\mathrm{Ag} / \mathrm{AgCl}$ & vs RHE & & \\
\hline Fe-N-G-HPC & $\sim 0.135$ & - & 3.99 & This work \\
\hline $\mathrm{Fe}_{0.3} \mathrm{Co}_{0.7} / \mathrm{NC}$ & & 0.88 & 3.85 & $\begin{array}{c}\text { Adv. Funct. Mater. 2018, 28, } \\
1706738 .\end{array}$ \\
\hline Fe-ISAs/CN & - & 0.9 & 3.9 & $\begin{array}{c}\text { Angew. Chem. Int. Ed. 2017, } \\
\text { 56, } 6937 .\end{array}$ \\
\hline $\mathrm{NFe} / \mathrm{CNs}-700$ & & 0.86 & 3.7 & $\begin{array}{c}\text { Adv. Mater. 2017, 29, } \\
1700707 .\end{array}$ \\
\hline Fe-N-C & - & 0.82 & 3.91 & $\begin{array}{c}\text { J. Mater. Chem. A 2017, 5, } \\
3336 .\end{array}$ \\
\hline p-CNT@Fe@GL & & 0.81 & 3.99 & $\begin{array}{c}\text { Adv. Mater. 2017, 29, } \\
1606534 .\end{array}$ \\
\hline
\end{tabular}




\begin{tabular}{|c|c|c|c|c|}
\hline $\mathrm{Fe} @ \mathrm{C}-\mathrm{FeNC}-2$ & - & 0.899 & $3.95-3.99$ & $\begin{array}{c}\text { J. Am. Chem. Soc. 2016, 138, } \\
3570 .\end{array}$ \\
\hline Fe3-NG & & 0.837 & $3.78-3.97$ & $\begin{array}{c}\text { Adv. Funct. Mater. 2016, } 26, \\
5708 .\end{array}$ \\
\hline $\mathrm{Fe}-\mathrm{N}-\mathrm{C}$ & 0.105 & - & $3.7-3.85$ & Nano Energy 2016, 30, 443. \\
\hline $\mathrm{Fe}, \mathrm{N} / \mathrm{PGC}-30$ & - & $\sim 0.82$ & $3.84-3.9$ & $\begin{array}{c}\text { J. Mater. Chem. A 2016, } 4 \text {, } \\
14364 .\end{array}$ \\
\hline Fe-NMCSs & & 0.82 & 4.05 & Adv. Mater. 2016, 28, 7948 \\
\hline $\mathrm{Fe} / \mathrm{N}-\mathrm{CNTs}$ & & 0.81 & 3.85 & $\begin{array}{c}\text { J. Mater. Chem. A 2016, 4, } \\
1694 .\end{array}$ \\
\hline $\mathrm{CNT} / \mathrm{PC}$ & - & 0.88 & 3.98 & $\begin{array}{c}\text { J. Am. Chem. Soc. 2016, 138, } \\
15046 .\end{array}$ \\
\hline PMF-800 & & 0.861 & 3.99 & $\begin{array}{c}\text { J. Am. Chem. Soc. 2015, 137, } \\
1436 .\end{array}$ \\
\hline $\begin{array}{c}\text { FePhen@MOF- } \\
\mathrm{ArNH}_{3}\end{array}$ & - & 0.86 & - & Nat. Commun. 2015, 6, 7343. \\
\hline Fe-N/C-800 & - & 0.81 & 3.95 & $\begin{array}{c}\text { J. Am. Chem. Soc. 2015, 137, } \\
5555 .\end{array}$ \\
\hline N-CC@CNTs & -0.08 & 0.88 & $3.83-3.94$ & Nanoscale 2014, 6, 8002. \\
\hline Fe-N/C-800 & & 0.809 & $3.94-3.99$ & $\begin{array}{c}\text { J. Am. Chem. Soc. 2014, 136, } \\
11027 .\end{array}$ \\
\hline FePc-Py-CNTs & - & 0.915 & 4.05 & Nat. Commun. 2013, 4, 2076. \\
\hline
\end{tabular}



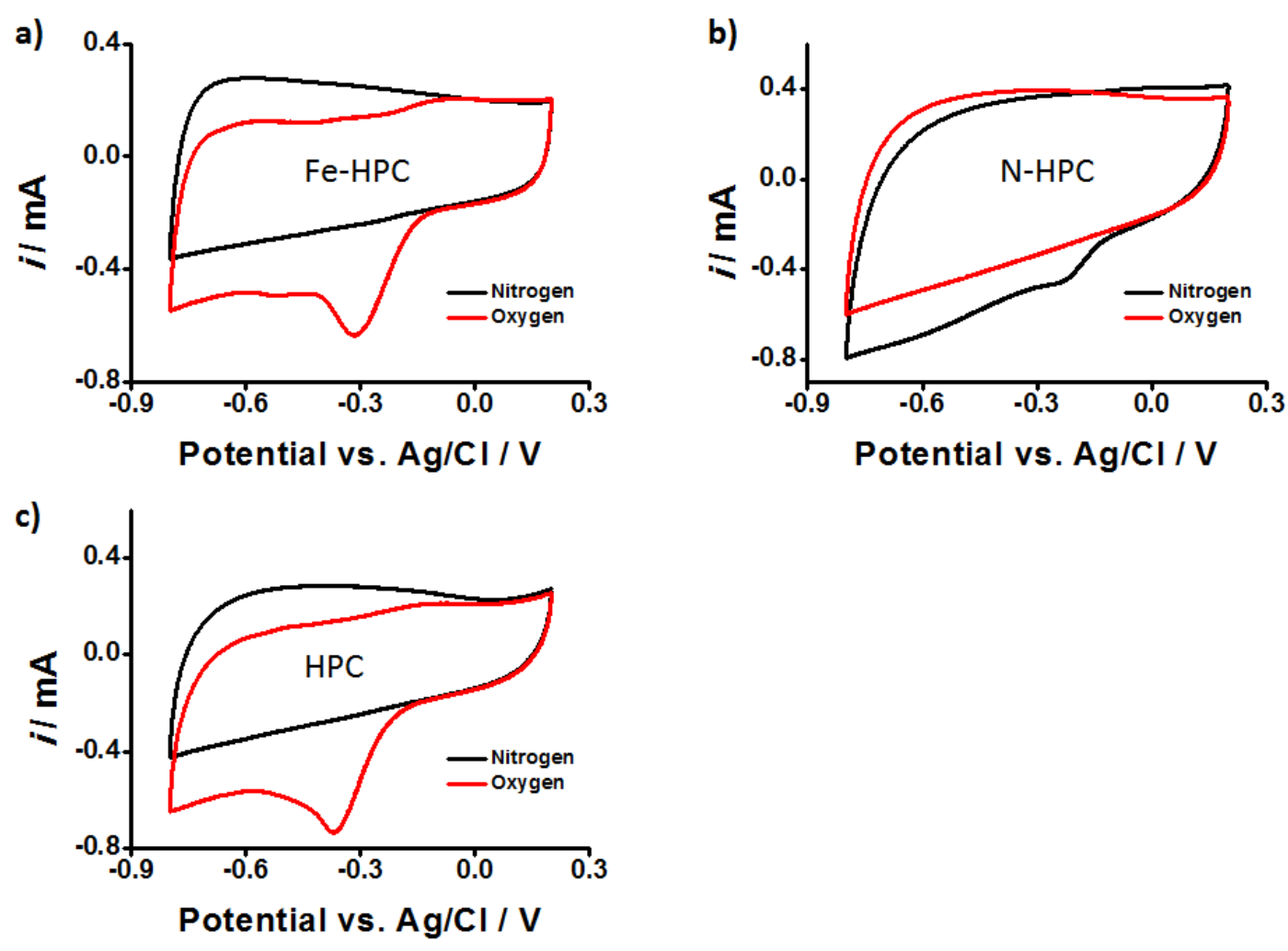

Figure S9. CV loops of (a) Fe-HPC, (b) N-HPC and (c) HPC samples. 

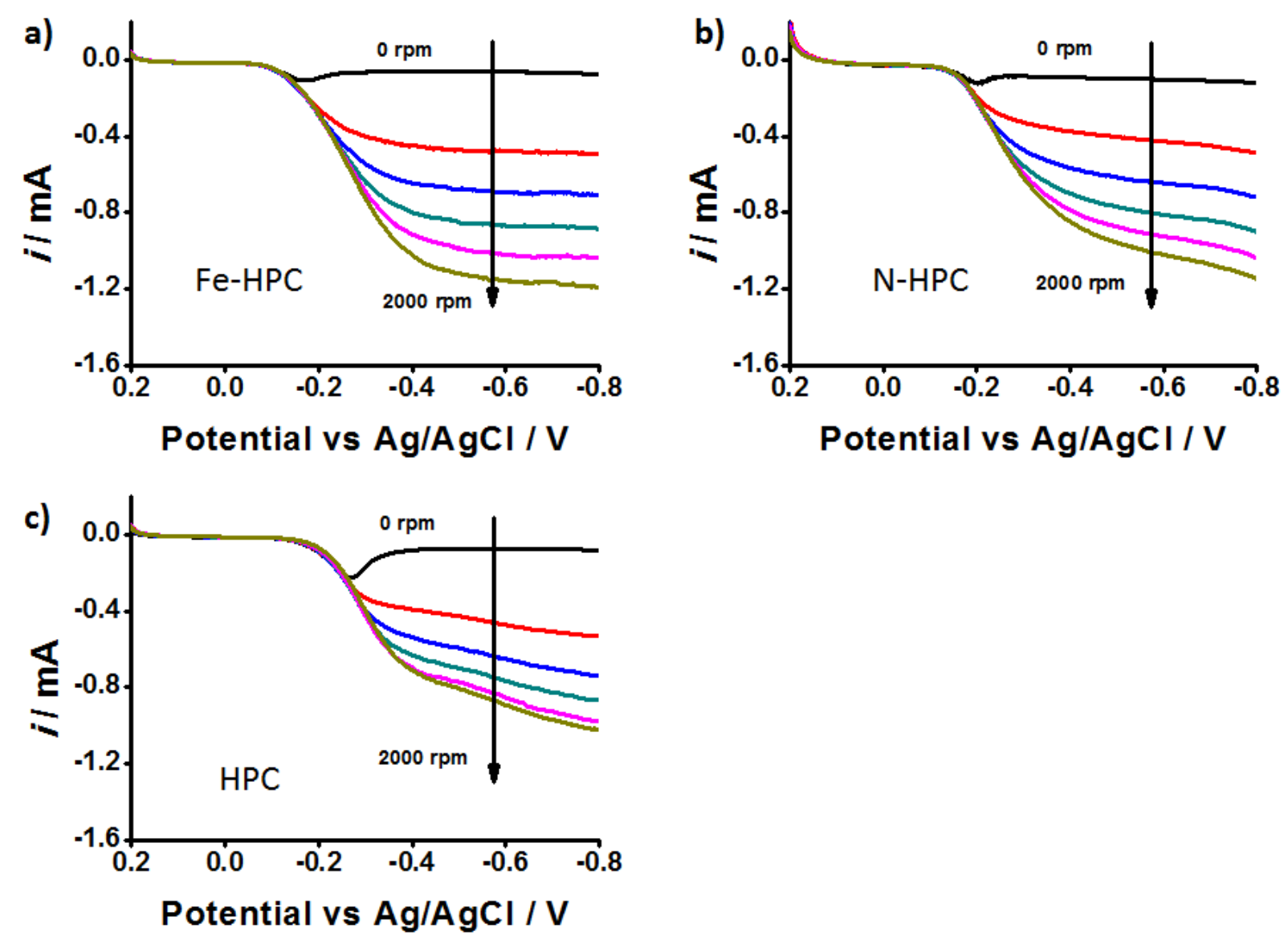

Figure S10. RDE voltammograms of (a) Fe-HPC, (b) N-HPC and (c) HPC samples. 

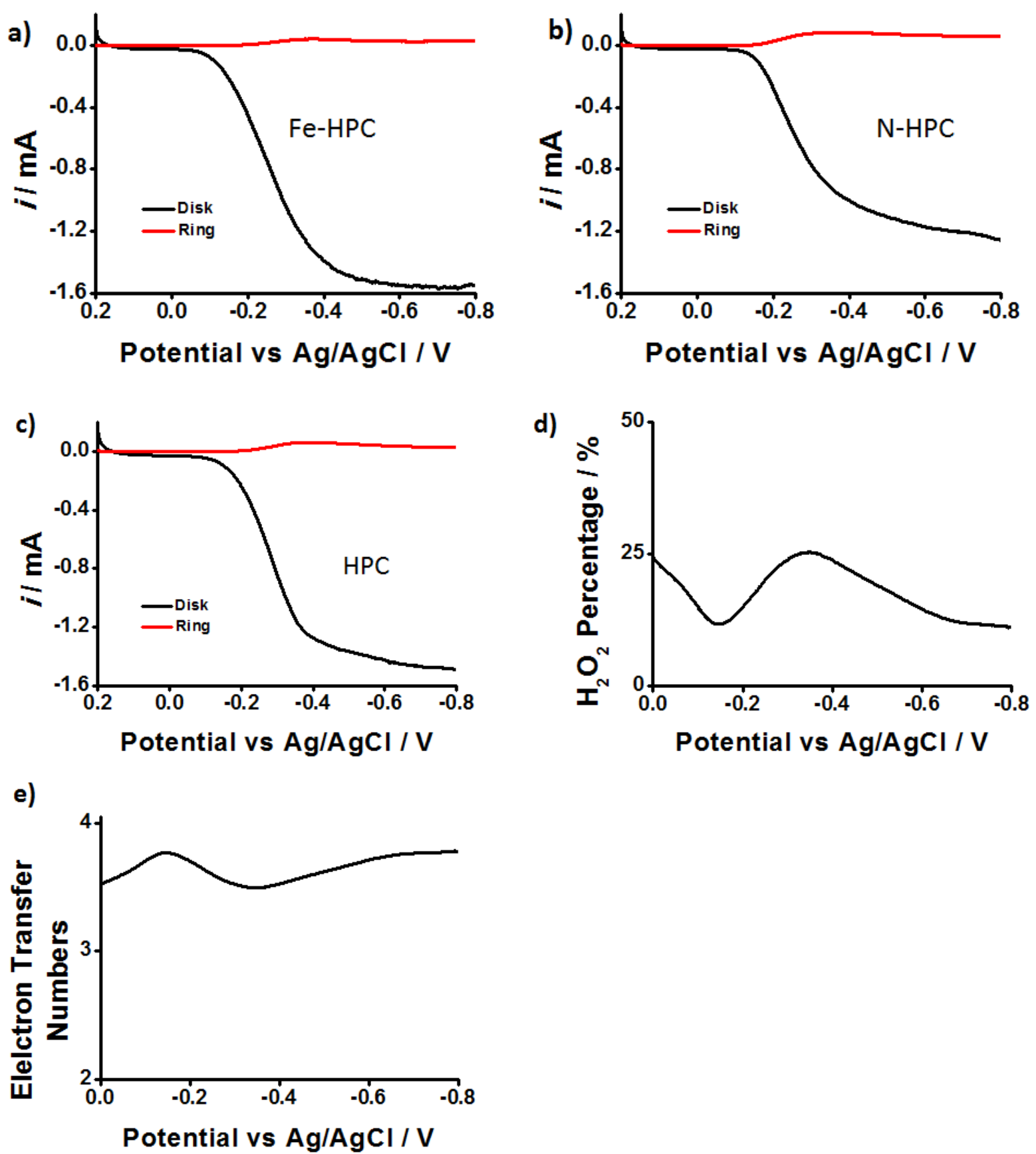

Figure S11. RRDE voltammograms at different rotating speeds of (a) Fe-HPC, (b) N-HPC and (c) HPC; (d) the peroxide product and (e) electron transfer numbers of HPC. 

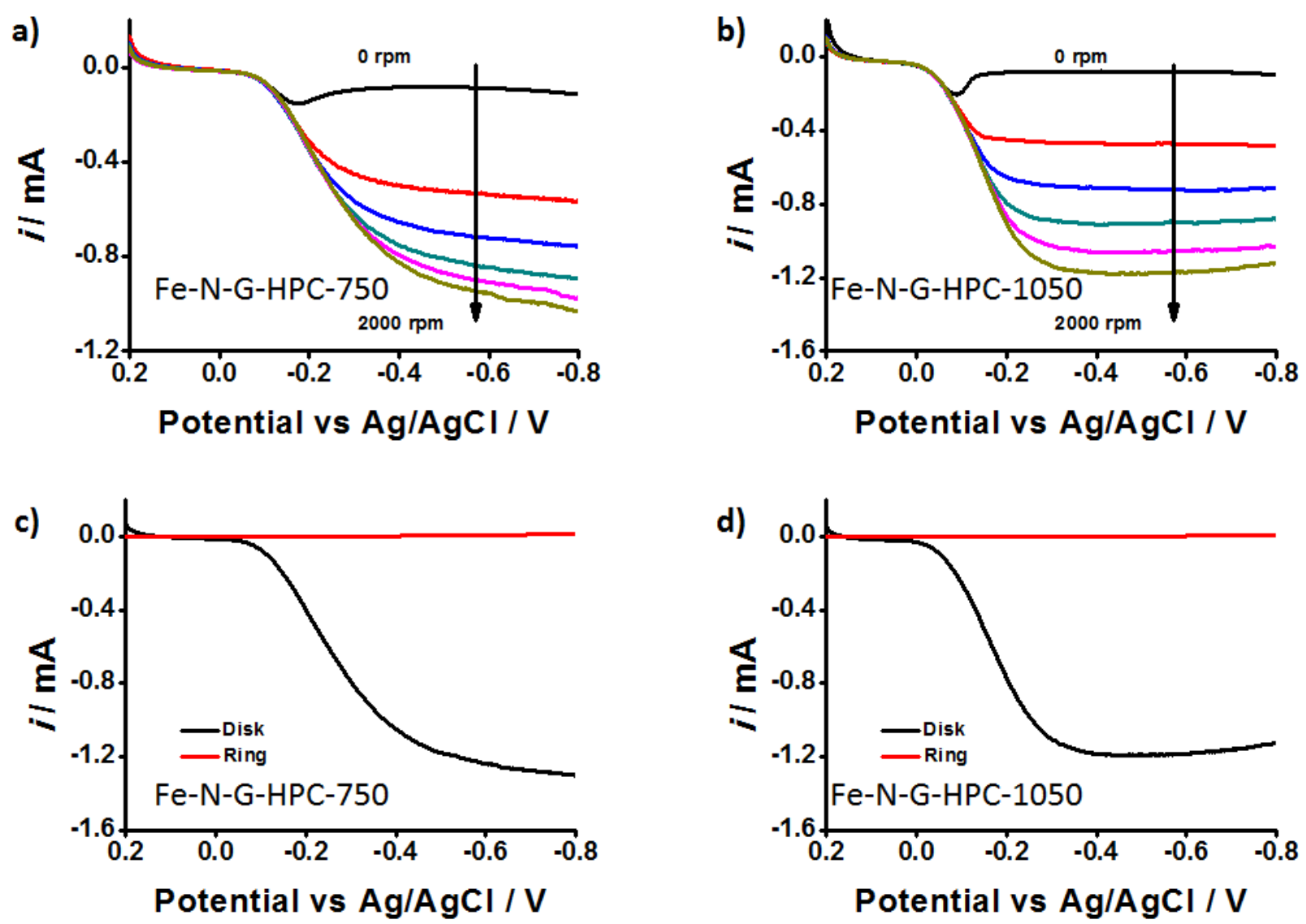

Figure S12. RDE voltammograms of different rotation speeds of (a) Fe-N-G-HPC-750 and (b) Fe-N-GHPC-1050; and the RRDE voltammograms of (c) Fe-N-G-HPC-750 and (d) Fe-N-G-HPC-1050. 

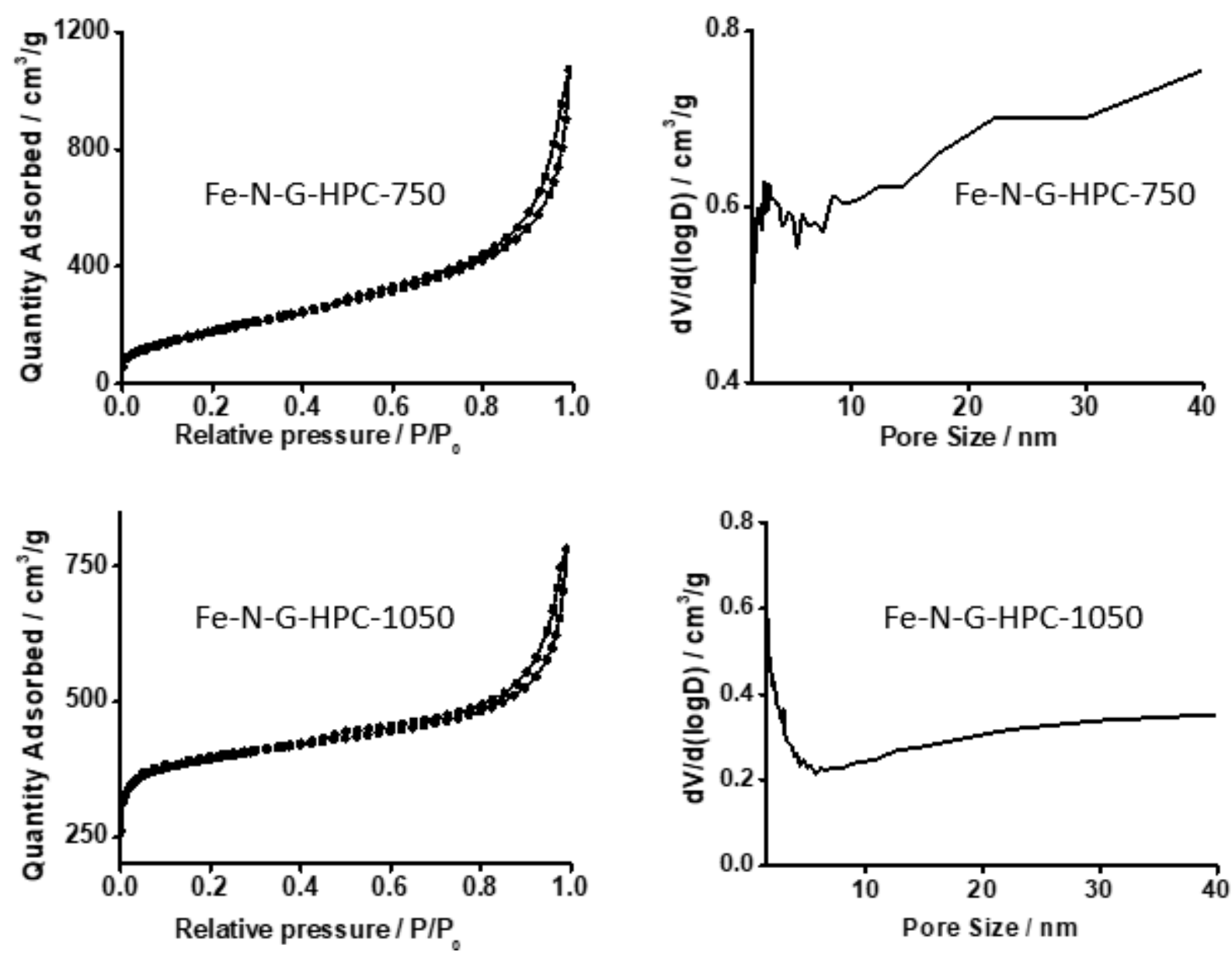

Figure S13. Nitrogen adsorption-desorption isotherms and the corresponding pore size distribution of (a, b) Fe-N-G-HPC-750 and (c, d) Fe-N-G-HPC-1050. 

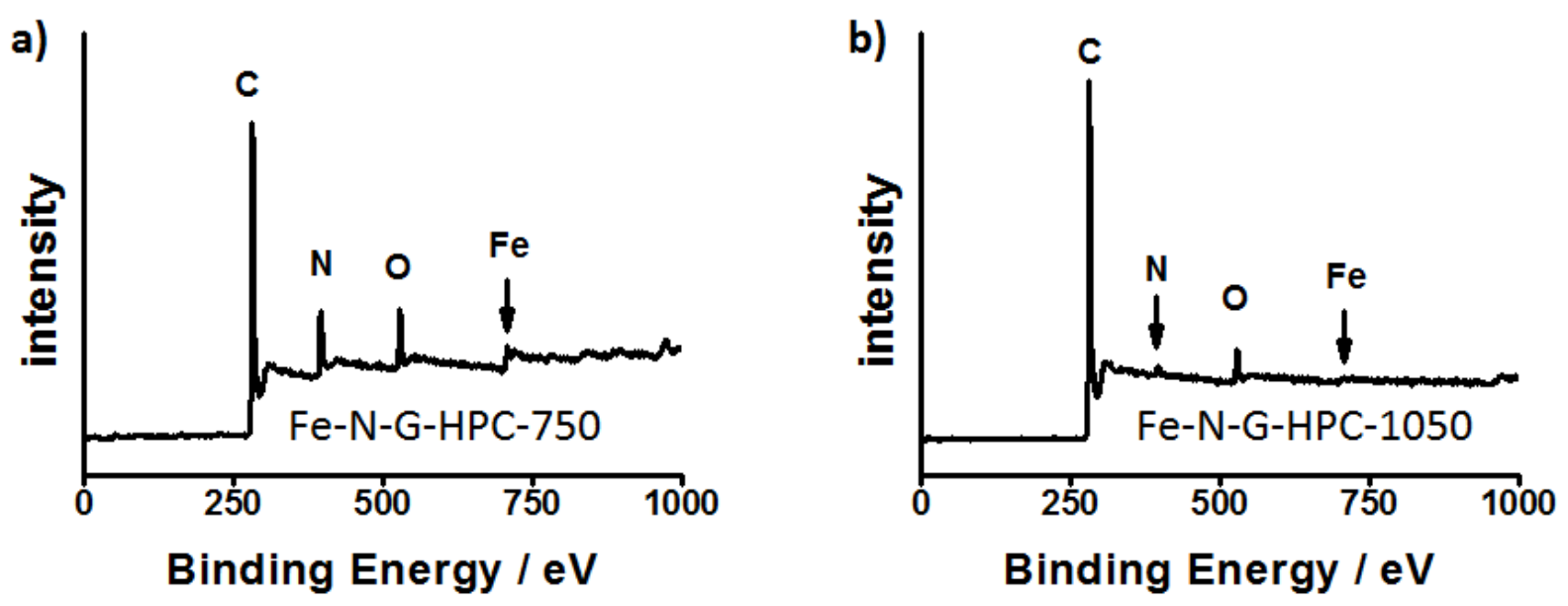

Figure S14. XPS survey scans of (a) Fe-N-G-HPC-750 and (b) Fe-N-G-HPC-1050.

Table S3. The element content of different samples obtained from the XPS results in Figure S14.

\begin{tabular}{ccccc}
\hline Content (at. \%) & Fe & N & O & C \\
\hline Fe-N-G-HPC-750 & 0.38 & 11.92 & 5.94 & 81.76 \\
Fe-N-G-HPC & 0.15 & 2.40 & 5.43 & 92.01 \\
Fe-N-G-HPC-1050 & 0.09 & 1.68 & 3.31 & 94.92 \\
\hline
\end{tabular}

It can be found that the Fe content decreased from $0.38 \mathrm{wt} . \%$ to $0.09 \mathrm{wt} . \%$ as the temperature increased from $750^{\circ} \mathrm{C}$ to $1050{ }^{\circ} \mathrm{C}$. Similar results have also been observed in other researches synthesizing Fe-N$\mathrm{C}$ materials at high temperatures. This might be resulted from Fe leaching at high temperatures, similar as for $\mathrm{N}$ elements. However, the exact reason for this still need further study. 